\title{
Review of Molecular Modeling and Photoelectronic Applications of Porphyrin- based Materials
}

M. MogrenAl Mogren, Noha M.Ahmed, Ahmed A.Hasanein

Chemistry Department, Faculty of Science, King Saud University, PO Box 2455, Riyadh 11451, Saudi Arabia

\section{Abstract}

In this review, the introduction of solar cells is presented. Old and new generation solar cells are briefly described. Quantum dot solar cells (QDSCs), perovskite solar cells, and dye-sensitized solar cells (DSSCs) are concisely introduced. The sensitization mechanism in DSSCs is discussed in detail concerning the spectral and electron injection properties of different dyes. An analysis of the intramolecular charge transfer process in the excited dye molecule is also provided. The use of porphyrin-based dyes as sensitizers in DSSCs is then reviewed. The design, synthesis, and photovoltaic application of a wide variety of porphyrin-based dyes as well as porphyrin dyads are presented and discussed. Theoretical studies of the spectral and electronic properties of different porphyrin-based dyes using DFT and TD-DFT methods are described. The different possibilities for improving the light-to-electrical energy conversion performance are discussed, such as structural modifications through introducing push-pull moieties, which in turn tunes the HOMO-LUMO energy gap of the sensitizing dye used in the DSSC. Experimental, as well as theoretical calculations of adsorption energies of the sensitizing dyes, are crucial for predicting the relative performance and efficiency of the dyes.

\section{Introduction}

Every day, 17.4 TW of energy is consumed globally. Most of this energy is still produced from fossil fuels - crude oil, coal, and natural gas account for $80 \%$ of the total energy produced [1]. Despite this being both environmentally harmful and economically unfavorable. The combustion of fossil fuels results in the release of 
various gases and organic compounds that cause air pollution as well as the heattrapping greenhouse effect. $\mathrm{CO}_{2}$ and other greenhouse gases such as methane, nitrogen oxides $\left(\mathrm{NO}_{\mathrm{x}}\right)$, and chlorofluorocarbons (CFCs) all absorb infrared (IR) radiation, which the Earth then radiates back to the atmosphere, causing an increase in temperature [2]. This process is already resulting in the melting of glaciers and sea ice in certain locations; if the polar ice caps were to melt, the sea level would rise, causing floods and even tsunamis.

Other very harmful climate changes can also occur, such as air pollution, causing greenhouse gases that encapsulate the atmosphere and prevent the moving of thermal reflection from the Earth to beyond the planet, causing a rise in earth's temperatures, increasing desertification and drought [3]. It should be clear to us that we can't depend on fossil fuels forever because they are nonrenewable faster enough to meet the daily needs of human beings, because they take decays to form inside the earth and at our existing habit rate [4], we will come to an end of fossil fuels use if we don't find other energy sources. Therefore it is essential to use other sources of energy such as renewable technologies like solar offer many more advantages, from dependability to lesser costs to smaller environmental effects [5].

Renewable energy sources (RES) such as solar energy have developed important choices to avoid the possible harmful environmental effects of constant fossil fuel use, it supplies $14 \%$ of the total world energy request. RES are biomass, hydropower, geothermal, solar, wind, and marine energies. The renewables are the main, domestic and clean or inexhaustible energy resources. The percentage share of biomass was $62.1 \%$ of total renewable energy sources in the nineteenth of this century. Research into different sources of energy stared in the late $90 \mathrm{~s}$ when the world started getting a problem from oil production due to price hiking [6].

The demand for energy and its related services is increasing. Therefore we need to return to sustain renewables to help alleviate climate change. To compete with fossil fuels, there are two main challenges for renewable energy devices; namely, efficiency and production costs [7]. The substituting fossil fuel-based energy sources with renewable energy sources would slowly achieve the idea of sustainability [8]. Governments and individuals in the world nowadays look ahead to reaching a maintainable future due to the changes formed in recent years to substitute petroleum- 
derived materials from fossil fuel-based energy sources with alternatives in renewable energy sources [9].

The cost of renewable energy is reducing and in some areas is cheaper than building gas or coal-fuelled power stations. The price of electricity obtained from renewable sources has been dropping reaching the point in it become cheaper than burning fossil fuels. The average costs of renewable technologies (RT) defeat those of fossil fuel technologies. RT coast onshore wind has fallen from $\$ 85$ to $\$ 83$ globally (solar photovoltaic has dropped from $\$ 129$ to $\$ 122$, offshore wind is falling from $\$ 176$ to $\$ 174$ ) but it lasting pricier than fossil fuel alternatives [10]. While fossil fuels are the opposite, the coal costs has jumped in many parts of the world (\$82 to $\$ 105$ in Europe, $\$ 66$ to $\$ 75$ in Americas, $\$ 68$ to $\$ 73$ in the Asia-Pacific). Also, combinedcycle natural gas plants have increased from $\$ 103$ to $\$ 118$ in EMEA and also climbed in other regions, reaching $\$ 82$ in the Americas and \$93 in the Asia-Pacific with coal and gas, the cost of nuclear power differs critically in different areas and is getting more expensive [11].

To understand cheap and efficient photovoltaic devices, solar cell technologies include an important field of research and the abundance of research in this area will be addressed in the following sections.

\section{Generation of solar cells (OGSC)}

The timeline of solar cells begins in the 19th century when it is observed that the presence of sunlight is capable of generating usable electrical energy [12]. Solar cells are usually divided into three main categories called generations up to recent years. The first generation contains solar cells that are relatively expensive to produce, and have a low efficiency. The second generation contains types of solar cells that have an even lower efficiency, but are much cheaper to produce, such that the cost per watt is lower than in first generation cells. The term third generation is used about cells that are very efficient [12].

Generally 1st generation's solar cells include a. Single Crystal Solar Cells b. Multi Crystal Solar Cells. This are the oldest and the mostly common used technology type due to high efficiencies. It made of semiconductor materials that contain a $\mathrm{p}-\mathrm{n}$ junction [12]. In this system electrons move toward the positive side (p) while the 
holes migrate to the negative one (n-side) of the junction, creating a potential difference across the junction [13]. This forms an electric field in the area of the connection that prevents further diffusion, as there is an imbalance of charge carriers on either side of the junction [13]. When light photons strike the surface of the cell, electrons are excited to the conduction band, leaving holes in the valence band. The electric field through the junction separates the holes from the electrons. When a load is placed between the two terminals, the electrons flow from p-type level to n-type level, where they recombine with the valence band holes; thus, current flows [13]. However, the light-to-electrical power conversion efficiency of the old generation solar cells was poor owing to many practical and theoretical considerations [14]. For example, the efficiency of silicon solar cells is limited to $29 \%$ because of the low bandgap of silicon $(1.1 \mathrm{eV})$ and the loss of solar energy absorbed as heat through a process known as thermalization. In addition to bulk silicon solar cells, there are two types of thin-film solar cells [15]. The first type is monocrystalline silicon solar cells, which consist of a layer of large single-crystal silicon that is grown under controlled conditions. These solar cells show efficiencies of up to $24.2 \%$, which is relatively high, but they lose their efficiency with increasing temperature [16]. The second type is polycrystalline silicon solar cells, which are composed of multiple silicon crystals. Although these solar cells are cheaper to manufacture, they have lower efficiencies $(\sim 12-14 \%)$ [17].

Another type of solar cell utilizes CdTe semiconductors. CdTe has a bandgap of $1.45 \mathrm{eV}$ and a high absorption coefficient, leading to rise in the efficiency $(22.1 \%)$ of CdTe-based solar cells [18], [19]. However, the toxicity of Cd, a heavy metal, is a major disadvantage of this type of solar cell. Copper-indium-gallium-selenium (CIGSe) solar cells are also of the thin film semiconductor generation. Their efficiency has been demonstrated to reach $22.6 \%$ [20], which makes them the highest performance thin-film solar cell.

\section{New generation solar cells}

The sharp increase of research passion in the new-generation solar cells in recent years has resulted in a new trend in combining multiple types of energy devices in a single device. 
In view of the enhanced and/or diversified function of integrated devices, as compared with conventional devices with limited performance or sole applicability, many integrated power packs have been widely developed by combining different devices, such as quantum dot solar cells (QDSCs), perovskite solar cells, and dye-sensitized solar cells (DSSCs). Some details of these solar cells are discussed in the following sections [18].

\subsection{Quantum dot solar cells (QDSCs)}

A quantum dot solar cell (QDSC) is a solar cell made to use quantum dots as the absorbing photovoltaic material to substitute most other materials. Quantum dots have bandgaps that are tunable across a wide variety of energy levels by altering their size. In bulk materials, the bandgap is fixed by the choice of material(s). This property makes QSCs attractive for multi-junction solar cells, where diversity of materials are used to enhance effectiveness by harvesting multiple portions of the solar spectrum [21].

QDSCs are composed of a nanoscale semiconductor such as porous Si or Ti [22]. In conventional Si solar cells, the incident ultraviolet (UV) light can be absorbed, producing heat rather than electricity. However, applying a layer of 1-nm-diameter silicon nanoparticles onto the silicon solar cells was found to increase the lightharvesting efficiency by up to 60\% [23], [24]. QDSCs create one of the most optimistic low-cost solutions that now are discovered for the world's requirements of clean and renewable energy. Efficient, low-toxic and stable QDSCs for large-scale applications for the solar cell research during recently [25].

This type of solar cell comprises a good alternative to ordinary silicon solar cells since they absorb energy in a wider wavelength range and are easy to prepare [23]. While the bandgap of bulk materials is fixed, the bandgap of quantum dots is tunable depending on the size of the nanoparticles used. Smaller nanocrystals absorb shorter wavelengths, while larger ones absorb longer wavelengths [25]. This could be used to monitor the bandgap energy by employing quantum dots of varying sizes. In ordinary solar cells, one photon excites one electron and creates one exciton (electron-hole pair). In contrast, in QDSCs, each absorbed photon can produce more than one 
electron, increasing efficiency [26]. Generally, the efficiency can reach $65 \%$ because of their advantageous properties and increased absorption of solar energy [26]. Another modern cell design is the dye-sensitized solar cell or DSSC. DSSCs use a sponge-like layer of $\mathrm{TiO} 2$ as the semiconductor valve as well as a mechanical support structure. During construction, the sponge is filled with an organic dye, typically ruthenium-polypyridine, which injects electrons into the titanium dioxide upon photoexcitation [23]. This dye is relatively expensive, and ruthenium is a rare metal [25].

Using QD as an alternative to molecular dyes was in use at the begging of DSSC research. Their tune bandgap ability permitted the designer to choose varied types of materials for different parts of the cell [27]. Some researchers enhanced a design built on the background electrode directly in contact with a film of quantum dots, removing the electrolyte and creating a depleted heterojunction. These cells reached 7.0\% efficiency, better than the best solid-state DSSC devices, but below those based on liquid electrolytes [28].

\subsection{Perovskite solar cells}

Perovskites materials have a similar crystal structure to calcium titanium oxide $\left(\mathrm{CaTiO}_{3}\right)$ [29], [30] with the general chemical formula of $\mathrm{ABX}_{3}$. A and $\mathrm{B}$ present two different sizes cations (A atom is larger than $\mathrm{B}$ atoms) while $\mathrm{X}$ is an anion link to both of them. The crystal structure of the perovskite materials is shown in Fig. 1. These compounds have a cubic unit cell, with A atoms occupying the corner positions, $\mathrm{B}$ atoms in the body-centered positions, and $\mathrm{X}$ atoms occupying the face-centered positions. Perovskites are divided into two major classes: inorganic (e.g. $\mathrm{SrTiO}_{3}[31]$ and organic. However, the third class of organic-inorganic hybrid perovskites exists, commonly known as organometal halides. Organometal halides are formed by replacing one of the cations from an inorganic perovskite with an organic cation, such as methylammonium (MA; $\mathrm{CH}_{3} \mathrm{NH}_{3}{ }^{+}$) [32], or formamidinium (FA; $\mathrm{NH}_{2} \mathrm{CHNH}_{2}{ }^{+}$) [33]. $\mathrm{MAPbI}_{3}$ and $\mathrm{MAPbI}_{x} \mathrm{Cl}_{3-\mathrm{x}}$ organometal halides are commonly used in perovskite solar cells fabrication [34]. 
(a)

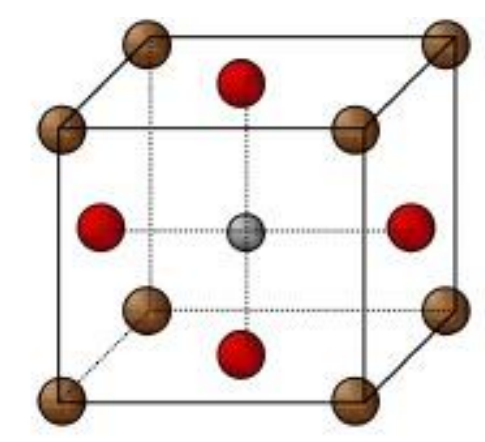

$\bigcirc \mathrm{Ba}^{2+} \bigcirc \mathrm{O}^{2-} \bigcirc \mathrm{Ti}^{4+}$ (b)
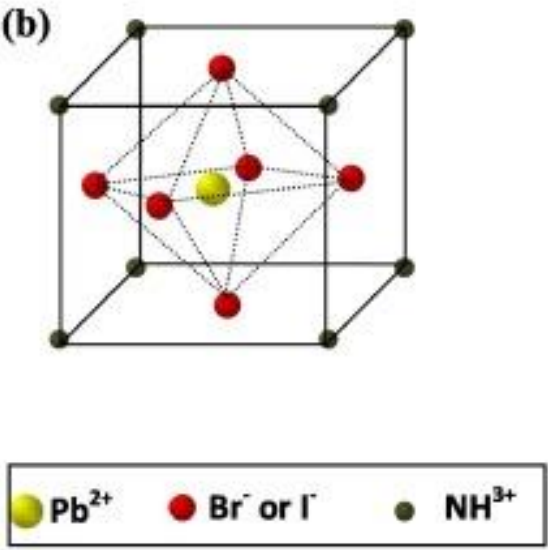

Fig. 1. Perovskite crystal structure.

Perovskite materials were first employed as light harvesters [35] in liquid electrolyte DSSCs, showing the efficiency of 3.8\%. Following this, perovskite quantum dotsensitized solar cells with slightly increased efficiency were fabricated based on nanocrystalline $\mathrm{MAPbI}_{3}$ perovskite sensitizer [36], [37]. A $3.6 \mathrm{~mm}$-thick perovskite quantum dot-sensitized nanocrystalline $\mathrm{TiO}_{2}$ film with an iodide/iodine (I-/I) based redox electrolyte was demonstrated to have an efficiency of 6.5\%. However, the efficiency and stability of the cell were significantly improved when using solid-state whole conductor or hole transporting material as a substitute to the liquid electrolyte [38]; the perovskite material injects electrons into the mesoscopic $\mathrm{TiO}_{2}$ and holes into the whole transport conductor [32].

Organometal halide perovskites have outstanding properties for use in solar cells. It has long electron-hole diffusion length, direct bandgap, large absorption coefficient, and long transporter lifetime [39], [40]. This type of Solar cells show efficiencies like $17.3 \%$ [41] and $12.8 \%$ at converting light energy into electricity. Such solar cells have drawn attention in the last decade due to their flexibility, low weight, and facile lowcost fabrication [42]. One of the major drawbacks of perovskite solar cells is the toxicity of $\mathrm{Pb}^{+2}$ inside $\mathrm{PbI}_{3}{ }^{-}$. Alternatives have been used, such as $\mathrm{Sn}^{+2}$, but it is too easily oxidized to $\mathrm{Sn}^{+4}$, which decreases the photovoltaic performance [43], [44]. Many processing technologies have been developed to form a uniform and pinholefree perovskite films, including solution processes and vapor deposition. Vapor deposition techniques tend to produce more uniform films than solution processing [45], [46], [47]. 


\subsection{Dye-sensitized solar cells (DSSCs)}

DSSCs are flexible, low-weight, and low-cost solar cells [48]. They harvest light energy with the assistance of dye molecules coated upon a nanocrystalline semiconductor photoelectrode. DSSCs are fabricated with a transparent conducting glass electrode (anode) coated with a thin film of transparent conductive oxide (TCO) [49] such as fluorine tin dioxide ( $\left.\mathrm{F}: \mathrm{SnO}_{2}\right)$ [50] to enhance the conductivity. The counter electrode (cathode) is coated with platinum [51] or graphite to increase its conductivity [52]. Under light absorption, the excited dye molecules emit electrons, so a redox couple electrolyte such as $\mathrm{I}^{-} / \mathrm{I}_{3}{ }^{-}[53]$ is used to compensate the lost electrons and regenerate oxidized dye molecules. Nanostructured $\mathrm{TiO}_{2}, \mathrm{ZnO}$, and $\mathrm{SnO}$ have been used as photoelectrodes [54], [55]. As well as being cheap, abundant, and nontoxic, $\mathrm{TiO}_{2}$ photoelectrodes are more stable than either $\mathrm{ZnO}$ or $\mathrm{SnO}$ even under extreme operating conditions. Of the three crystalline forms of $\mathrm{TiO}_{2}$ (rutile, anatase, and brookite [56]), anatase has the most advantageous properties, including a wide bandgap $(3.2 \mathrm{eV})$ that makes it more chemically stable at low temperatures, and a high packing density that allows fast transport of electrons in the photoelectrode [57]. A schematic representation of this type of cell is given in Fig. 2.

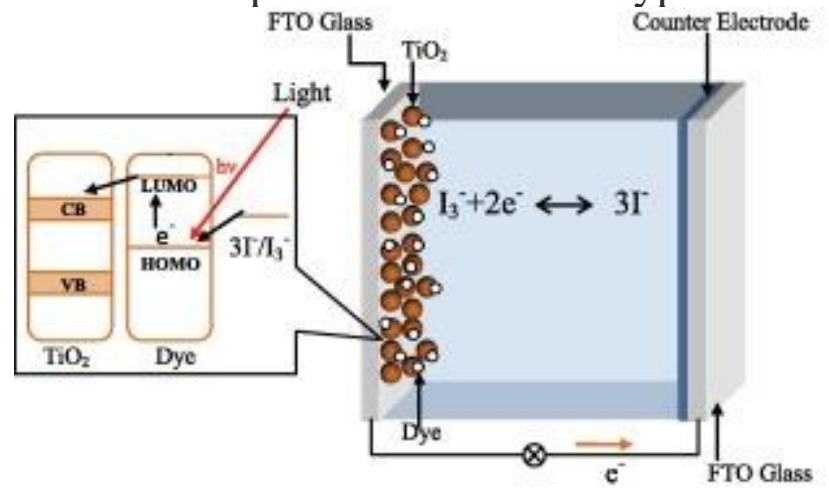

Fig. 2. Schematic representation of DSSCs.

\subsubsection{Sensitization mechanism}

The mechanism of sensitization in DSSCs is based on multistep pathways [58]. The first step is photoexcitation: a dye molecule absorbs a photon and gets excited to its first singlet excited state. The excited dye molecule then injects an electron to the surface of the $\mathrm{TiO}_{2}$ nanocrystalline particles, either spontaneously or after relaxation. Radiation relaxation of the excited dye, in addition to the possible recombination of injected electrons with the oxidized dye, can reduce the performance of the 
DSSC [59], [60]. The injected electrons subsequently transfer by diffusion through the $\mathrm{TiO}_{2}$ film to the external electric circuit. The redox couple electrolyte helps to regenerate the oxidized dye molecules into their reduced form. These processes are summarized in the following chemical reactions [60]:

Photoexcitation: (Dye molecule) $+\mathrm{h} \nu \rightarrow($ Dye molecule)*

Electron injection: (Dye molecule) $)^{*} \rightarrow(\text { Dye molecule })^{+}+\mathrm{e}^{-}\left(\mathrm{TiO}_{2}\right)$

Electron diffusion: $\mathrm{e}^{-}\left(\mathrm{TiO}_{2}\right) \rightarrow \mathrm{e}^{-}$(wire)

Electron transfer to electrolyte: $\mathrm{I}_{3}^{-}+2 \mathrm{e}^{-}$(counter electrode) $\rightarrow 3 \mathrm{I}^{-}$

Dye regeneration: 2(Dye molecule) ${ }^{+}+3 \mathrm{I}^{-} \rightarrow 2$ (Dye molecule) $+\mathrm{I}_{3}{ }^{-}$

Recombination with dye: (Dye molecule $)^{+}+\mathrm{e}^{-} \rightarrow$ (Dye molecule)

Recombination with electrolyte: $\mathrm{I}_{3}{ }^{-}+2 \mathrm{e}^{-} \rightarrow 3 \mathrm{I}^{-}$

Relaxation: (Dye molecule) $*$ (Dye molecule)

The electrolyte in a DSSC should be carefully selected. It should be transparent to visible light and not react with the dye molecules [61]. Three types of electrolytes have been used in DSSCs: liquid electrolytes, solid-state electrolytes such as ionicliquid-based imidazolinium salts, and quasi-solid gel forms of electrolyte. Organic and ionic liquid electrolytes are used, where an organic electrolyte is composed of a redox couple and solvent [62]. Among the many redox couples, $\mathrm{I}^{-} / \mathrm{I}_{3}{ }^{-}$is the most commonly used in DSSCs due to its low light absorption in the visible region, suitable redox potential, and fast dye regeneration process [63].

The photosensitizer dye is the most crucial component in DSSCs. It absorbs solar energy and converts it to electrical energy. It should show high photostability for a long time without degradation as well as high thermal and electrochemical stability. It should also be an efficient light harvester; that is, it should intensively absorb a bigger part of the visible and near-IR spectrum. Its lowest unoccupied molecular orbital (LUMO) level should be higher in energy than the conduction band edge of the $\mathrm{TiO}_{2}$ semiconductor to increase the probability of electron injection from the excited dye molecule to the semiconductor layer [64]. To achieve effective dye renewal, the highest occupied molecular orbital (HOMO) should lie below the energy level of the redox couple.

Dye sensitizers are mainly classified into three groups: $\mathrm{Ru}$ (II) complexes, other metal complexes, and metal-free organic sensitizers [65]. Metal complex sensitizers have 
anchoring and ancillary ligands. The attaching ability of the sensitizer to the $\mathrm{TiO}_{2}$ surface is determined by the anchoring ligand, while the overall properties of the sensitizer can be tuned by the ancillary ligand. The efficiency of the solar cell thus depends on the molecular structure of the sensitizing dye as well as that of the anchoring and ancillary ligands [66]. Ruthenium (II) based metal complexes show high efficiencies as dyes. The metal complex dye cis-RuL $\mathrm{L}_{2}-(\mathrm{NCS})_{2}$, termed N3, exhibits a conversion efficiency of $10.3 \%$ [67]. Another dye (termed "black dye") demonstrated an energy conversion efficiency of $10.4 \%$. Greater conversion efficiency of $11.2 \%$ was obtained using a dye named N179, which is similar to N3 [68]. The chemical structure of these dyes is shown in Fig. 3. However, while a host of metal complexes have been tested as sensitizers for DSSCs [69], there is a limit application as dye sensitizers due to some undesirable characters such as manufacture cost, length of synthesis and purification time. This motivated researchers to search for metal-free organic as well as natural dyes for photosensitizers in DSSCs.

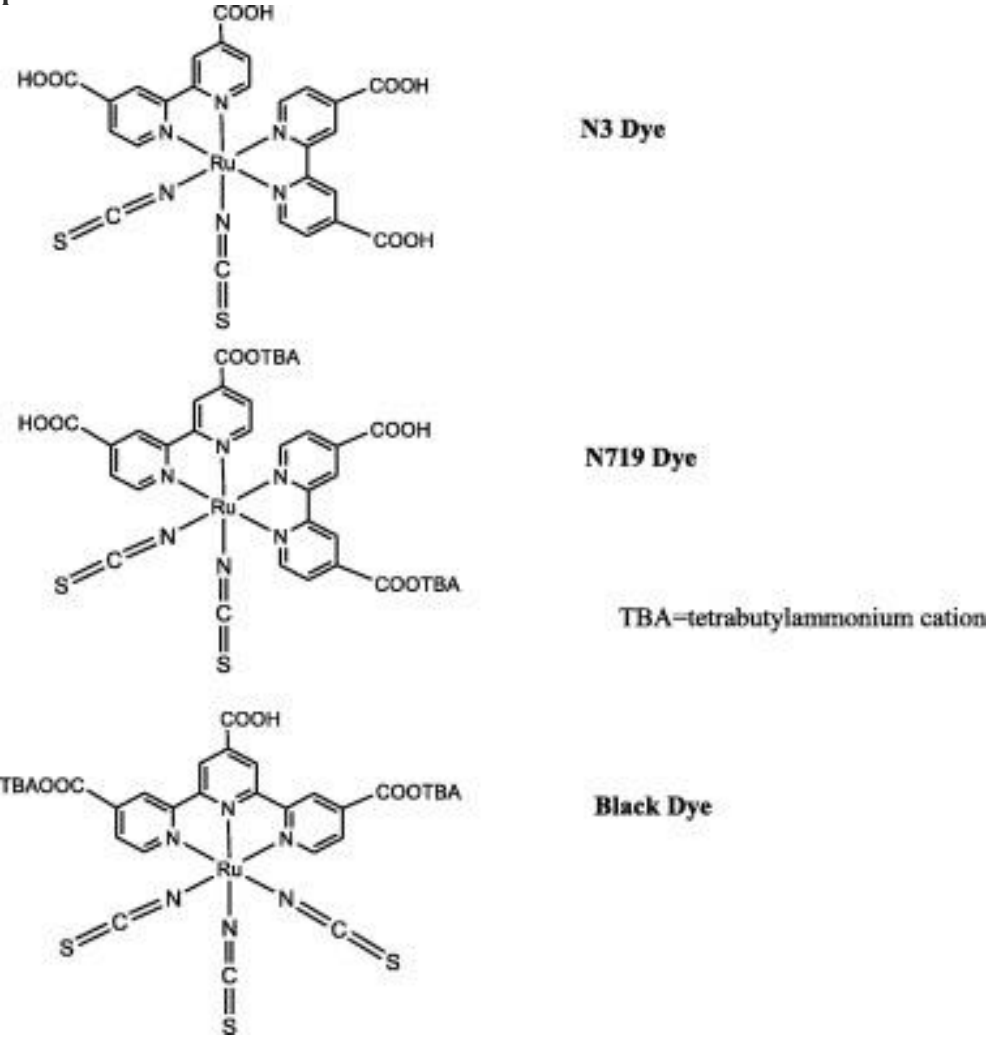

Fig. 3. Chemical structures of N3, N719, and Black dye. 
Recently, many types of research have been carried out in exploring metal-free organic sensitizers both experimentally and theoretically to predict their efficiency as sensitizers in DSSCs [70]. This type of sensitizer has many advantages. For example, the chemical structure of the dye can be modified to improve its sensitization performance. Structural modification can enhance the light-harvesting efficiency, leading to greater extinction coefficients compared to metal complex sensitizers. They are also of low cost [71].

The general design of a metal-free organic sensitizer is based on a push-pull structural moiety with the general form D- $\pi$-A (Fig. 4), where D is an electron donor group linked to an electron acceptor group A through a $\pi$-conjugated moiety ( $\pi$-bridge) [60]. During photoexcitation, the electron density shifts from the donor part of the dye molecule (where the HOMO is localized) to the electron acceptor (where the LUMO is localized), leading to electron injection into the conduction band of the nanocrystalline semiconductor $\left(\mathrm{TiO}_{2}\right)$. The sensitization process strongly depends on the electron-donating and accepting ability of both donor-acceptor part, and the electronic properties of the $\pi$-bridge used [67]. The $\pi$-bridge conjugated part is based on some chemical groups such as coumarin, phenoxazine, oligothiophene, etc., While the donor groups can be found in dialkylamine, diphenylamine, triphenylamine, etc. [58]. Carboxylic acid, rhodanine-3-acetic acid, and cyanoacrylic acid moieties are frequently used as acceptor groups anchoring onto the $\mathrm{TiO}_{2}$ surface [62], [68].

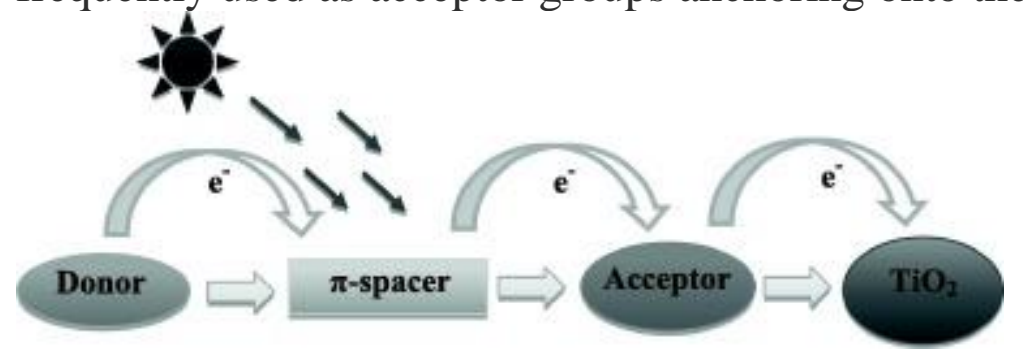

Fig. 4. D- $\pi$-A model of the sensitizing dye.

Hundreds of modeled metal-free organic dyes are described in the literature for use as sensitizers in DSSCs, with noteworthy efficiencies reported such as $10.1 \%$. However, there are many drawbacks related to this type of sensitizer: they are possibly toxic and cause environmental pollution; the purification process is demanding, and the sensitizer tends to degrade with time [66], [67], [68], [69]. Besides, molecular aggregation on the $\mathrm{TiO}_{2}$ surface can reduce the electron injection to the conduction 
band of $\mathrm{TiO}_{2}$, decreasing the efficiency [60]. The aggregation problem could be overcome by adding long alkyl chains and aromatic groups into the dye structure or by using co-adsorbents. The co-adsorbents keep the molecules physically separate [72]. The most popular co-adsorbents are chenodeoxycholic acid, hexadecylmalonic acid, and dineohexyl bis(3,3-dimethylbutyl)phosphinic acid [73]. Naturally occurring dyes have also attracted attention for use as sensitizers in DSSCs. Natural pigments have many merits, including ease of preparation, easy access, relative abundance, high purity grade, environmental friendliness, and low production cost [74]. They include carotenoids, betalains, flavonoids, and chlorophyll. However, natural dyes have low efficiency because of weak bonding with the semiconductor surface [75], [76]. Efforts to improve their efficiency include mixing two or more pigments to increase their light absorption capability and using different solvents to improve dye extraction and bonding between the dye molecule and semiconductor surface [77].

The dyes extracted from both pomegranate and berry fruits were effectively used in the manufacture of natural dye-sensitized solar cells (NDSSC). The morphology, porosity, surface roughness, and other psychochemical characters were investigated by several analytical techniques including FESEM, EDS, TEM, etc. Pomegranate dye contains anthocyanin which is the outstanding pigment needed for the production of electricity [78].

The solar cell's photovoltaic performance in terms of efficiency, voltage, and the current was tested and showed different parameters. After optimization of the photoanode and other rest of the other characters were improved and impedance determination exhibited a moderately low charge-transfer resistance (17.44 $\Omega$ ) and a long lifetime, demonstrating a reduction in recombination losses. The enhanced efficiency is attributable in part to the use of a highly concentrated pomegranate dye, graphite counter electrode and $\mathrm{TiCl}_{4}$ treatment of the photo-anode [79], [80].

\subsubsection{Cell efficiency and electron injection properties}

The performance of DSSCs is typically assessed by the solar-to-electrical energy conversion efficiency, $\eta$, which is the overall efficiency of converting sunlight to electricity. It can be expressed by the following

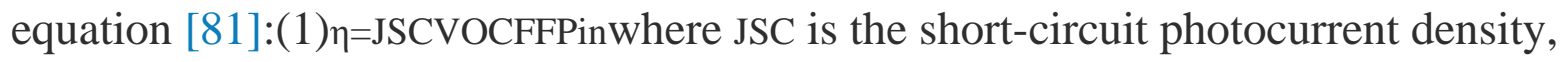
which can be determined when the voltage is zero; VOC is the open-circuit 
photovoltage, which can be determined when the current is zero; FF is the fill factor, and Pinis the intensity of the incident light. The fill factor FF is a ratio of the maximum power of the solar cell (Pmax) and the product of JSC and VOC. Its value can be between 0 and 1 , and it describes the current-voltage curve. Another measure of performance for DSSCs is the incident photon-to-current conversion efficiency (IPCE), which is the short-circuit photocurrent density (JSC) in the external circuit divided by the cell's exposure to a photon flux. JSC depends on the dye absorption coefficient and interaction between the dye and nanocrystalline $\mathrm{TiO}_{2}$ surface. It can be calculated by the next

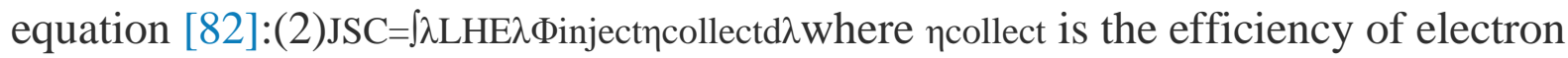
collection; Фinject is the quantum yield of electron injection; andLHE $\lambda$ is the lightharvesting efficiency at a given wavelength, which can be calculated [80] as(3)LHE $\lambda=1-10-\mathrm{f}=1-10-\mathrm{A}$ where $\mathrm{A}$ is absorbance and $\mathrm{f}$ is oscillator strength at wavelength $\lambda$. Higher oscillator strength results in better light-harvesting efficiency upon absorbing light, and in turn an increased JSC value. The fill factor parameter is only obtained experimentally. The following relation has been proposed [83], [84] to correlate the open-circuit voltage VOC (in units of electron volt; $\mathrm{eV}_{\mathrm{oc}}$ ) with the electronic structure of the dye:(4)eVOC=ELUMOECBSCwhere ECBSC is the reduction potential of the conduction band of the $\mathrm{TiO}_{2}$ semiconductor, which can be taken as $-4.0 \mathrm{eV}$ [83]. Increasing the quantum yield of electron injection (Фinject) from the excited dye molecules to the conduction band of the semiconductor enhances the performance of the DSSC. After the electron injection process the efficient regeneration of oxidized dye molecules by the redox

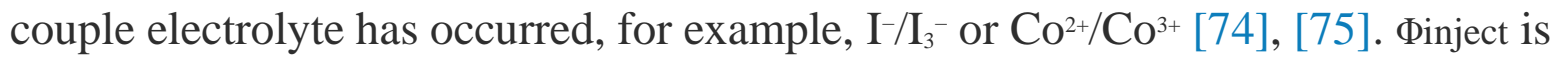
related to the free energy change of the electron injection process $\Delta$ Ginject, which is expressed [84], [85] as(5) $\Delta$ Ginject=Eoxdye*-ECBSCwhere Eoxdye* is the oxidation potential of the dye in its excited state.

When evaluating Eoxdye*, we must consider whether the electron injection process occurs spontaneously after vertical excitation of the dye or after relaxation. If we assume that the process occurs spontaneously, the following equation can be used [85]:(6)Eoxdye*=Eoxdye- $\lambda \max (1)$ where $\lambda \max (1)$ is the wavelength of the lowest energy maximum absorption of the electronic transition in (UV-vis) of the dye absorption spectrum. 
This electronic transition is described by the HOMO $\rightarrow$ LUMO excitation. The term Eoxdye refers to the redox potential of the ground state, which could be taken as the negative orbital energy of the HOMO by applying Koopman's theorem [84]. However, if the electron injection process is assumed to occur after the relaxation of the excited dye molecule, the following relation can be used [85]:(7)Eoxdye*=EoxdyeE0-0dyewhere E0-0dye is the energy difference between the ground state and the relaxed excited state and is given as(8)E0-0dye $=\lambda \max (1)$-ES1reorgSince the reorganization energy of the $S_{1}$ state (ES1reorg) is approximately $0.5 \mathrm{eV}$ [86], [87], the calculation of $\Delta$ Ginject assuming spontaneous injection (Eq. (6)) is reliable.

\subsubsection{Analysis of charge transfer in an excited dye molecule}

According to the charge transfer (CT) model proposed by Le Bahers, Adamo, and Ciofini [88], [89], the partial atomic charge of any atom (i) whose Cartesian coordinates are $\left(\mathrm{x}_{\mathrm{i}}, \mathrm{y}_{\mathrm{i}}\right.$, and $\left.\mathrm{z}_{\mathrm{i}}\right)$ changes upon excitation of the dye molecule from its ground state (GS) to its excited state (ES) with an amount $\Delta q_{i}$ given as(9) $\Delta q i=\Delta$ qiES$\Delta \mathrm{qiGS}\{=\mathrm{qi}+\mathrm{if} \Delta \mathrm{qi}>0$ and $=\mathrm{qi}$-if $\Delta \mathrm{qi}<0$

Upon excitation, the atoms that lose electronic charge hold a partial charge of qi+; and those that gain electronic charge hold qi-. The amount of intramolecularly transferred charge $\mathrm{qCT}$ can be calculated as $(10) \mathrm{qCT}=\sum$ iqi $+=\sum$ iqi-

The Cartesian coordinates of the two barycenters corresponding to the qi+ and qi- functions are defined as $(11) \mathrm{r}+=\mathrm{x}+, \mathrm{y}+, \mathrm{z}+=\sum$ iriqi $+\mathrm{qCT}$ andr- $=\mathrm{x}-\mathrm{y}-\mathrm{y}-\mathrm{z}-\sum$ iriqi-qCT The charge transfer distance dCT and dipole moment change $\Delta \mu \mathrm{CT}$ of the molecule as a result of the electronic excitation can be calculated as $(12) \mathrm{dCT}=\mathrm{r}+\mathrm{r}-\mathrm{and} \Delta \mu \mathrm{CT}=\mathrm{dCTqCT}$ For a rod-like system in which the charge transfer takes place along the x-axis, an index denoted as $\mathrm{H}$ is employed, which is defined as:(13) $\mathrm{H}=\sigma+\mathrm{x}-\sigma-\mathrm{x} 2$ where $\sigma \pm \mathrm{x}=\sum \mathrm{iqi} \pm \mathrm{xi}-$ $\mathrm{x} \pm 2 \mathrm{qCT}$ where $\sigma \pm \mathrm{x}$ is the root mean square deviation for the positive or negative components along the $\mathrm{x}$-axis. The t-index is used as a descriptor of the difference between the calculated $\mathrm{dCT}$ and $\mathrm{H}$ values, which is defined [90] as $(14) \mathrm{t}=\mathrm{dCT}-\mathrm{H}$

\subsubsection{Quantum chemical parameters $(Q C P)$}

QCP such as electron affinity, ionization potential, chemical potential, electrophilicity, and hardness can be calculated from the orbital energies of the highest and lowest occupied molecular orbital ( $\left.\mathrm{E}_{\text {номо }} \& \mathrm{E}_{\mathrm{LUмо}}\right)$ using the relations given below. The electrophilicity index $(\omega)$ is defined as an amount of the reduction in energy that occurs due to the maximal transfer of electrons from a donor to an 
acceptor system [91], [92]. It can be calculated using the following equation;(15) $\omega=\mu 22 \eta w h e r e ~ \mu$ and $\eta$ are the chemical potential [93] and hardness [94], respectively.

The chemical potential, hardness, and electronegativity $(\chi)$ is expressed in terms of ionization energy (I) and electron affinity (A) as follows, where $(\chi=-\mu):(16) \mu=\partial \mathrm{E} \partial \mathrm{Nvr} \approx-\mathrm{I}+\mathrm{A} 2 \mathrm{and} \chi=\mathrm{I}+\mathrm{A} 2(17) \eta=\partial \mu \partial \mathrm{Nvr} \approx \mathrm{I}-\mathrm{A}$ Using Koopmans' approximation [86], I and A can be expressed in terms of the $\mathrm{E}_{\text {номо }}$ and $\mathrm{E}_{\text {Luмо }}$ energies as follows:(18)I -EHOMO(19)A $\approx-$ ELUMO Many applications of the theoretical approaches described in 3.3.2 Cell efficiency and electron injection properties, 3.3.4 Quantum chemical parameters (QCP) can be found in the literature [93], [94].

\subsection{Polymer solar cells (PSC)}

Polymer solar cells, also known as a plastic solar cells. It is a layered structure consisting of, at a minimum, a transparent front electrode, an active layer and a back electrode printed onto a plastic substrate [95]. The documented maximum energy alteration efficiency currently is $10 \%$. To further progress the act, new polymers with numerous molecular structures and their uses in photovoltaic devices are recently discovered [96].

Coupling solar energy with solar cells built on organic materials (especially PSC) is an excellent substitute to SBSC due to the benefits of lesser weight, flexibility, and lower manufacturing costs, easier integration with other products, and low environmental impact during manufacturing and short energy payback times. Also its efficiencies reported up to 17\% [97], [98]. The PSC performance parameters include open-circuit voltage (VOC), short-circuit current density (JSC) which are created from the intrinsic properties of the photoactive polymer [99], [100].

\subsection{Tandem cells (TC)}

Tandem cells of various configurations today are on the agenda of many research teams all around the world to overcome theoretical limits for single-cell efficiency $(\sim 30 \%)$. It can be any combination of existing solar cells based on $\mathrm{Si}, \mathrm{GaAs}$, CIGS, Perovskites, etc. The tandem cell is the result of looking for more efficient ways to 
improve existing technology. It can be grouped depending on materials used to organic, inorganic and hybrid, and then classification goes deeper to further details [101].

\subsubsection{Organic tandem cells (OTC)}

Organic photovoltaics are cheap cells, with small or medium effectiveness. It has power conversion efficacies of $>10 \%$. OTC is estimated to reach $15 \%$ and considered to be the most demandable cell because it's cheap and semi-transparency but unfortunately it has low efficiency [102].

\subsubsection{Inorganic tandem cells (ITC)}

ITCs are prepared from III to V group materials that are called mother and father of the technology. The world-record efficiency of 3 junction cell comprises of GaInP/InGaAs/InGaAs, which showed $44.4 \%$ effectiveness under 302 suns, whereas a four-junction GaInP/GaAs; GaInAsP/GaInAs reach $46.0 \%$ at 508. These types of cells are used mainly in space applications, like satellites or with difficult and expensive concentrator systems, because of very high price yet highest efficiencies [101].

\subsubsection{Hybrid tandem cells (HTC)}

HTC is where the perovskite combined with other materials, this combination has strong optical absorption and long diffusion length and ability. DSSC also is an example of another type of solar cell, with a fascinating structure, in complete transparency and low price. These cells are used for its semitransparent and flexible modules properties. Using them in tandem has many perspectives, because it is flexible, semi-transparent, and can reduce the price of the solar industry. Efficiencies of these tandems here range from 8 to more than $17 \%$ [103].

\section{Porphyrin-based dyes as sensitizers for DSSCs}

The conversion of light energy into electrical energy using solar cells has become a key field of research. The great need for materials that can be used for solar energy conversion led to a wide variety of dyes being used as photosensitizers in DSSCs [104], [105], [106], [107], [108]. Several organic and inorganic dyes have been employed owing to their low cost and reasonably high efficiency. This also motivated theoretical studies to recognize the correlation between the dye chemical structure and its molecular electronic properties with the sensitization process. This subject has been reviewed by different authors [109], [110], [111], [112], [113]. 
After ruthenium-based dyes, researchers turned to porphyrin-based dyes (both metalloporphyrins and metal-free porphyrins) for use as photosensitizers in DSSCs [114], [115], [116], [117], [118]. Porphyrins are important naturally occurring macrocyclic compounds. They have a characteristic ring structure with a central cavity which exhibits remarkable ligation capability toward metal cations yielding different metalloporphyrins [116]. Their electronic spectra display two main absorption regions: a strong Soret band in the range of 250-500 nm, and relatively weak bands (Q bands) in the range of 550-700 nm [119], [120], [121]. Experimental as well as theoretical interpretations of the electronic transitions corresponding to these absorption bands have been explicitly performed [122], [123], [124], [125], [126], [127], [128], [129], [130]. The interesting optical, photochemical, and photophysical properties of porphyrins and metalloporphyrins led to their comprehensive use as photosensitizers for producing electrical energy in photovoltaic devices and DSSCs [131], [132], [133], [134], [135], [136], [137], [138]. During the last two decades, numerous porphyrin-based dyes have been designed with structural modification to introduce different electron-donating and electron-accepting species. The aim was to enlarge the $\pi$-system to increase light-harvesting and obtain highly efficient sensitizers for DSSCs [139], [140], [141], [142], [143], [144]. Various promising porphyrins have been designed, and their electronic structure and excitation properties, in addition to their photon-to-current efficiencies, have been explicitly investigated both experimentally and theoretically [145], [146], [147], [148], [149]. The photophysical properties of some structurally diverse near-infrared cyanine dyes were investigated under a variety of conditions [150], [151]. The dyes absorbed light of a wavelength within the range of 779-823 $\mathrm{nm}$ and emitted within the range of 832$876 \mathrm{~nm}$. The dyes had fluorescence quantum yield in the range of $14-22 \%$. The elemental analysis and morphology of the cyanine dye-sensitized photoanodes showed unique characters. The accuracy of the fabricated cyanine dye-sensitized solar cells was evaluated using current-voltage and electrochemical impedance spectroscopic measurements. The solar-to-electric power conversion efficiency ranged from $0.04 \%$ to $0.24 \%$ [150].

Porphyrins present in some biomolecules and can be also synthetically made to be used in probe components of chemical and biological sensors. Two different 
porphyrin dyes were investigated, they contained of a metal-free 5, 10, 15, 20-mesotetrakis-(9H-2-fluorene-yl) porphyrin $\left(\mathrm{H}_{2} \mathrm{TFP}\right)$ and its Zinc complex (ZnTFP).

Photophysical Analysis of the two dyes was carried out to evaluate their absorption, emission, and binding characteristics. [151], [152]. The metal-free porphyrin were found to be more influential than the zinc complex. The impedance measurement showed less whole resistance for the free porphyrin $(50 \Omega)$ compared with the zinc complex (130 $\Omega)$. [151].

Photocurrent (Jsc) and photovoltage (Voc) are two important parameters for dyesensitized solar cells (DSSCs) to achieve high power conversion efficiencies (PCEs) four new porphyrin dyes were synthesized (XW36-XW39) using an N-phenylsubstituted phenothiazine donor to pursue higher PCE. For XW36 and XW37, the Nphenyl group is wrapped with two ortho-alkoxy chains [153]. On the contrary, it is substituted with a para-alkoxy group in XW38 and XW39. The phenothiazine wrapping in XW36 and XW37 induces more serious distortion, which is helpful for anti-aggregation but unfavorable for the electron transfer from donor to a porphyrin framework. The result of this study provides an effective strategy for developing efficient DSSCs by the targeted co-adsorption and sensitization of porphyrin sensitizers optimized through introducing a bis(ortho-alkoxy)-wrapped phenyl group into the phenothiazine donor and/or methyl groups into the benzoic acid acceptor unit [153], [154].

\subsection{Design and synthesis of efficient porphyrin-based dyes for DSSC applications}

The kinetics of interfacial electron transfer with the sensitizing efficiency of different dyes have been investigated by some scintests [122]. They compared three dyes: $\mathrm{Ru}$ (2,2-bipyridyl-4,4-dicarboxylate) $)_{2}$-cis-(NCS $)_{2}$, tetracarboxyphenyl porphyrin $\left(\mathrm{H}_{2} \mathrm{TCPP}\right)$, and $\mathrm{Zn}$ tetracarboxyphenyl porphyrin (ZnTCPP), which have similar carboxylate groups for binding to the $\mathrm{TiO}_{2}$ surface. It was found that although they show great variances in their oxidation potentials, they have nearly the same kinetics of interfacial electron transfer after optical excitation in addition to adsorption to the nanocrystalline $\mathrm{TiO}_{2}$ films. 
Tetra (4-carboxyphenyl) porphyrin dye (TCPP) was reported to have adsorption onto $\mathrm{TiO}_{2}$ nanoparticulate and worked as an effectual photosensitizer for solar-energy alteration [124]. Both X-ray photoelectron spectroscopy (XPS) and resonance Raman spectroscopy (RRS) was used to study the nature of TCPP binding onto the $\mathrm{TiO}_{2}$. In the XPS both TCPP and $\mathrm{TiO}_{2}$ spectra showed that both $\mathrm{O}(1 \mathrm{~s})$ and $\mathrm{Ti}(2 \mathrm{p} 3 / 2)$ peaks of $\mathrm{TiO}_{2}$ were moved to $0.3 \mathrm{eV}$ higher binding energy value, while peaks of TCPP $(\mathrm{O}$ and $\mathrm{N}$ ) were moved to $0.7 \mathrm{eV}$ higher binding energy. On the other hand, using RRS both TCPP and $\mathrm{TiO}_{2}$ spectra were similar to each other, this is representative of the domination of porphyrin-porphyrin interactions, this led to the discovering of good solar-energy conversion efficiencies made from $\mathrm{TCPP}$ and $\mathrm{TiO}_{2}$ [124]. Using sun simulated light (AM 1.5), TCPP sensitized cell by showed short-circuit photocurrent $\left(6 \mathrm{~mA} / \mathrm{cm}^{2}\right)$ and an open-circuit photopotential $(485 \mathrm{mV})$. The occurrence of cell photon-to-current change effectiveness was 55\% and 25-45\% for Soret peak and Qband peaks respectively. The obtained cells fill factor FF was 60-70\% with 3\% overall energy conversion efficiency [126].

Two porphyrin derivatives [5-(4-carboxyphenyl)-10,15,20-tritolylporphyrin $\left(\mathrm{H}_{2} \mathrm{TC} 1 \mathrm{PP}\right)$ and 5,10,15,20-tetrakis(4-carboxyphenyl)porphyrin $\left.\left(\mathrm{H}_{2} \mathrm{TC} 4 \mathrm{PP}\right)\right]$ were photoelectrochemical and photochemical investigated [129]. UV-vis and IR were used for recording the interaction between the porphyrin and $\mathrm{TiO}_{2}$ electrode and proved that there is a difference in adsorption behavior for both of them. The IR spectra suggested that both these two porphyrins adsorb onto the $\mathrm{TiO}_{2}$ surface by either bridging or bidentate chelate direction due to the influence of the different number of carboxyl groups on the photoelectrochemical properties of the cell, this is occurs by the absorbance of carboxylate groups onto the $\mathrm{TiO}_{2}$ surface using bidentate chelation method [124]. Spectroscopic analysis showed that for the porphyrins with carboxylic binding to diamagnetic $\mathrm{Zn}$ or $\mathrm{Cu}$ containing (metalloporphyrins) affect the photon-to-current exchange efficacies ( $\mathrm{Zn}$ higher than $\mathrm{Cu}$ ) [125]. Also, porphyrins coupling with a phosphonate group shows lesser effectiveness than those with a carboxylate attaching group. These findings helped in the modeling of suitable porphyrins which absorb visible light near IR of the solar spectrum to improved efficiency of solar cells [128].

Some porphyrins (free-base) were synthesised to be used as photosensitizers in $\mathrm{TiO}_{2}$ DSSCs [127]. These sensitizers were attached to the surface of $\mathrm{TiO}_{2}$ through 
carboxylic acid or phosphonic attaching groups at different substitution positions on the porphyrin moiety. The photoelectrochemical activities as sensitizers were compared to one of the known sensitizer $(5,10,15,20$-tetra(4carboxyphenyl)porphyrin), Notably, the nature of phosphonic or carboxylic acids was found to has little effect on the cell performance, while the position of substitution attaching groups on the porphyrin powerfully stimulate the photon-to-current conversion effectiveness of the consequential cell [126]. A further series of porphyrin dyes were designed and synthesized [131] with different electron-donating groups attached at the meso-position. The spectral, as well as electrochemical and photovoltaic properties of all the designed porphyrin dyes, were found to be significantly affected by the presence of an electron-donating group. The absorption spectra of porphyrins with an amino group showed a broadened Soret band and redshifted Q bands for those of the reference porphyrin. The HOMO-LUMO energy gap was found to decrease upon the introduction of an electron-donating group at the meso-position. Results of density-functional theory (DFT) calculations supported these findings [132]. Among the synthesized dyes, the best cell performance obtained was with an overall efficiency of $6.6 \%$ of power conversion under simulated one-sun AM 1.5 illumination [135]. A novel molecular design of a D- $\pi$-A porphyrin sensitizer in which 2,1,3-benzothiadiazole moiety is used [136], [137] as the $\pi$-conjugated linker between the porphyrin core and benzoic acid as the acceptor group. A dye termed as GY50 was used as a sensitizer in DSSCs with a redox mediator based on cobalt tris (bipyridine) in acetonitrile showed a power - conversion efficiency of $12.75 \%$. Panda et al. [139] synthesized and characterized a further series of porphyrin-based dyes to be used as photosensitizers for DSSCs. These push-pull type porphyrin dye molecules contained a porphyrin unit as a $\pi$-spacer, two $\mathrm{N}, \mathrm{N}^{\prime}$-dimethyl phenyl groups as electron donors, and two phenyl carboxylic acid moieties as anchoring groups. The photophysical and electrochemical properties of these dyes were examined using fluorescence spectroscopy, cyclic voltammetry, and UV-vis. DFT calculations were also performed [135]. The results exhibited that the HOMO was positioned on the donor group while the LUMO was positioned on the attaching carboxylate group, representing their suitability for effective sensitization in DSSCs. Under photovoltaic measurements, the overall photon-to-current efficiency reached $6.07 \%$, especially 
when a co-adsorbent such as chenodeoxycholic acid (CDCA) was added to the dye solution.

Synthesizing and design of $\mathrm{D}-\pi-\mathrm{A}$ structured $\mathrm{Zn}(\mathrm{II})$-porphyrin sensitizers with extended $\pi$-conjugation were investigated [155] They studied the effect of the donor capability and bulk of donor groups on the photophysical properties and cell performance. Also, the co-sensitization process was evaluated to enhance the cell presentation, based on the photophysical results obtained. It was found that porphyrins containing a strong donor unit exhibit similar Soret band absorption and a slightly redshifted Q-band absorption. To further extend the $\pi$-conjugation and absorption at longer wavelengths, they introduced a triple bond at two meso-positions of the porphyrin ring and a strong electron acceptor benzothiadiazole group. This resulted in a red-shift and broad visible region absorption ability, and in turn, a higher lightharvesting efficiency. A co-adsorbent was also adopted, and the photon-to-current conversion efficiency reached 9.6-10.2\% [156]. The experimentally measured efficiencies and their chemical structures of some designed, sensitized and experimentally tested porphyrin-based dyes are shown in Fig. 5 and Table 1. 
I (Ar=1,3-di-tert-butyl phenyl)
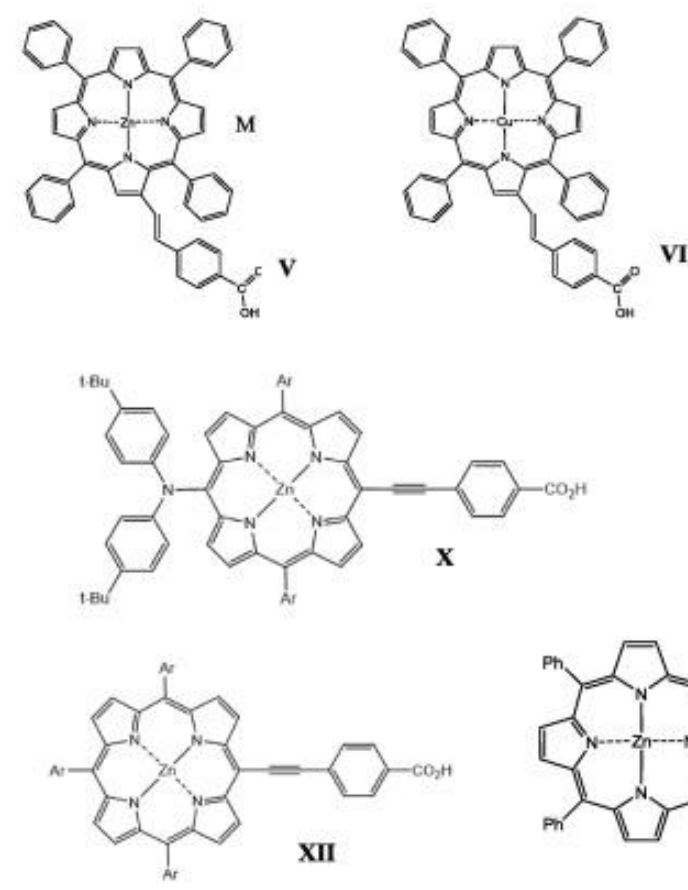
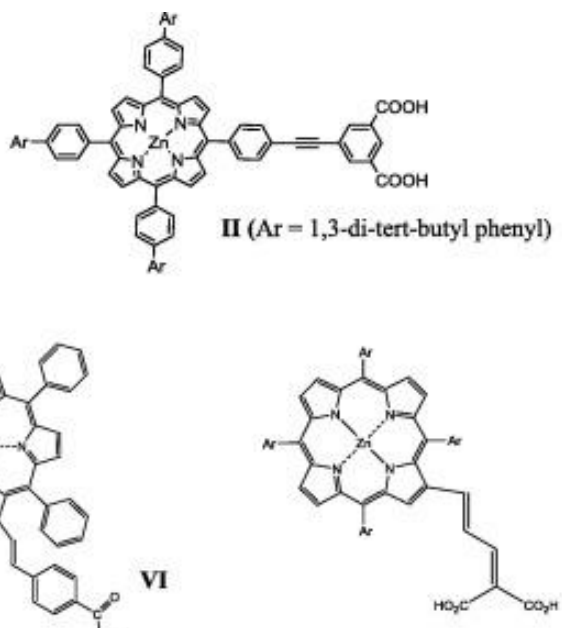

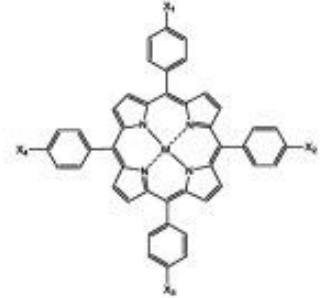

III (M=2H, $\mathrm{X}_{1}=\mathrm{X}_{2}=\mathrm{X}_{3}=\mathrm{X}_{4}=\mathrm{H}$ )

IV $\left(=2 \mathrm{H}, \mathrm{X}_{1}=\mathrm{X}_{2}=\mathrm{X}_{3}=\mathrm{X}_{4}=-\mathrm{COOH}\right)$

XV (M=2H, $\left.\mathrm{X}_{1}=\mathrm{X}_{3}=-\mathrm{NH}_{2}, \mathrm{X}_{2}=\mathrm{X}_{4}=\mathrm{COOH}\right)$ XVI $\left(\mathrm{M}=\mathrm{Zn}, \mathrm{X}_{1}=\mathrm{X}_{3}=\mathrm{NH}_{2}, \mathrm{X}_{2}=\mathrm{X}_{4}=\mathrm{COOH}\right)$ VII (Ar-Ph)

VIII (Ar= 4-methylPh)

IX (Ar= 4-n-butylPh)

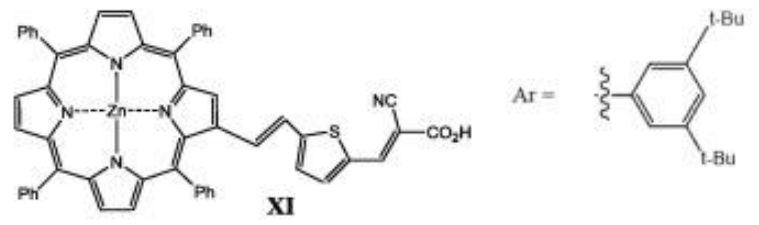

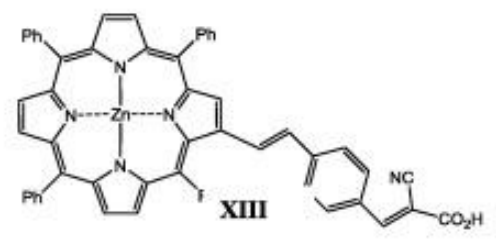

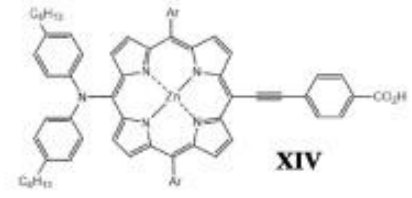

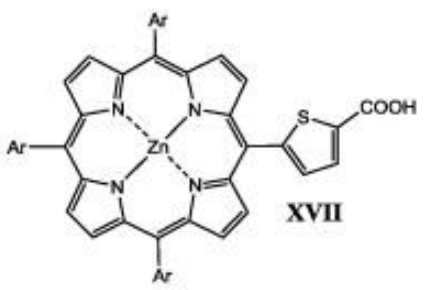

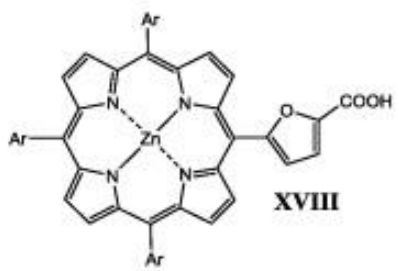

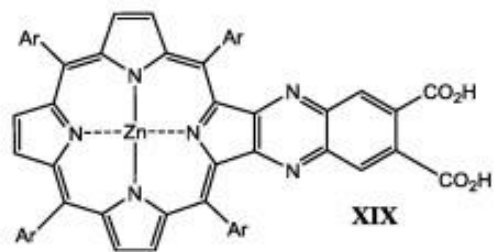

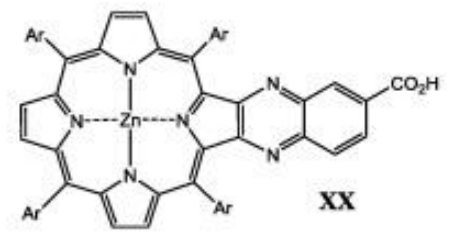<smiles>Cc1cc(C)c(C#N)c(C)c1</smiles>

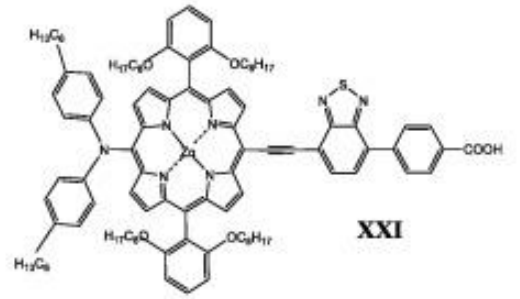

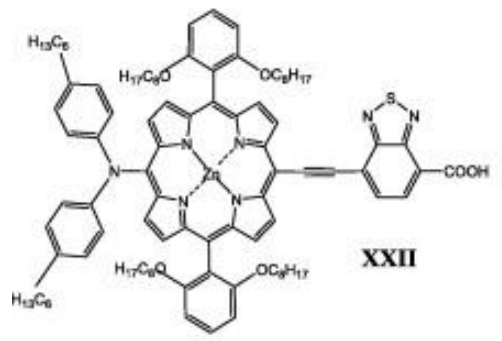

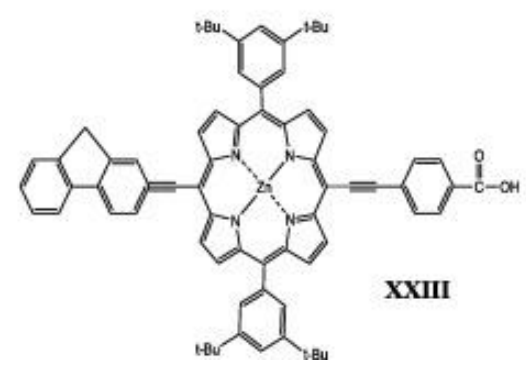

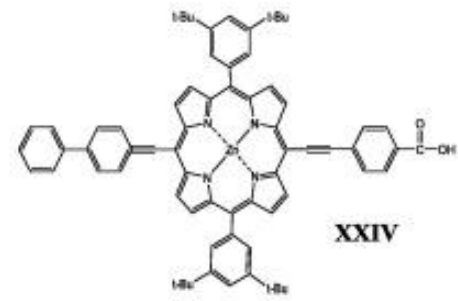


Fig. 5. Some designed, sensitized and experimentally tested porphyrin based dyes.

Table 1. Experimental efficiency of some porphyrin based dyes which are showed Fig. 5.

\begin{tabular}{|c|c|c|c|c|c|c|c|}
\hline Dye & $\eta \%$ & Redox Couple (solvent) & Ref & Dye & $\eta \%$ & Redox Couple (solvent) & Ref \\
\hline I & 2.40 & $\mathrm{I}-/ \mathrm{I} 3-\left(\mathrm{CH}_{3} \mathrm{CN}\right)$ & 62 & XIII & 6.15 & I-/I3-(THF) & 129 \\
\hline II & 2.70 & $\mathrm{I}-/ \mathrm{I} 3-\left(\mathrm{CH}_{3} \mathrm{CN}\right)$ & & XIV & 6.56 & I-/I3-(THF) & \\
\hline III & 0.006 & I-/I3-(DMF) & 121 & $\mathrm{XV}$ & 3.80 & $\mathrm{I}-/ \mathrm{I} 3-\left(\mathrm{CH}_{3} \mathrm{CN}\right)$ & 135 \\
\hline IV & 0.36 & I-/I3-(DMF) & & XVI & 4.83 & $\mathrm{I}-/ \mathrm{I} 3-\left(\mathrm{CH}_{3} \mathrm{CN}\right)$ & \\
\hline V & 4.11 & I-/I3-(THF) & 124 & XVII & 3.10 & $\mathrm{I}-/ \mathrm{I} 3-\left(\mathrm{CH}_{3} \mathrm{CN}\right)$ & 142 \\
\hline VI & 0.45 & I-/I3-(THF) & & XVIII & 2.30 & $\mathrm{I}-/ \mathrm{I} 3-\left(\mathrm{CH}_{3} \mathrm{CN}\right)$ & \\
\hline VII & 5.10 & $\mathrm{I}-/ \mathrm{I} 3-\left(\mathrm{CH}_{3} \mathrm{CN}\right)$ & 126 & XIX & 5.20 & $\mathrm{I}-/ \mathrm{I} 3-\left(\mathrm{CH}_{3} \mathrm{CN}\right)$ & 145 \\
\hline VIII & 7.10 & $\mathrm{I}-/ \mathrm{I} 3-\left(\mathrm{CH}_{3} \mathrm{CN}\right)$ & & $\mathrm{XX}$ & 4.00 & $\mathrm{I}-/ \mathrm{I} 3-\left(\mathrm{CH}_{3} \mathrm{CN}\right)$ & \\
\hline IX & 6.40 & $\mathrm{I}-/ \mathrm{I} 3-\left(\mathrm{CH}_{3} \mathrm{CN}\right)$ & & XXI & 12.75 & $\mathrm{Co} 2+/ \mathrm{Co} 3+\left(\mathrm{CH}_{3} \mathrm{CN}\right)$ & 132,133 \\
\hline $\mathrm{X}$ & 3.70 & $\mathrm{I}-/ \mathrm{I} 3-\left(\mathrm{CH}_{3} \mathrm{CN}\right)$ & 128 & XXII & 2.52 & $\mathrm{Co} 2+/ \mathrm{Co} 3+\left(\mathrm{CH}_{3} \mathrm{CN}\right)$ & \\
\hline XI & 1.20 & $\mathrm{I}-/ \mathrm{I} 3-\left(\mathrm{CH}_{3} \mathrm{CN}\right)$ & & XXIII & 6.30 & I-/I3-(THF) & 151 \\
\hline XII & 4.34 & I-/I3-(THF) & 129 & XXIV & 8.10 & I-/I3-(THF) & \\
\hline
\end{tabular}

\subsection{Synthesis and photovoltaic applications of porphyrin dyads}

Some workers [137] established an appropriate technique for the synthesis of porphyrin-derived dyads. Porphyrin dyads could have interesting applications as electronic materials. The solar-to-electrical energy conversion using a $\mathrm{SnO}_{2}$ electrode and porphyrin dyads has been investigated, demonstrating that these compounds might be suitable for solar energy conversion devices. A porphyrin dyad with the structural moieties 5-(4-carboxyphenyl)-10,15,20-tris(4-methylphenyl)porphyrin (P) and $\mathrm{Zn}$ (II) 5-(4-carboxyphenyl)-10,15,20-tris(4-methylphenyl)porphyrin (P-Zn) was found to generate a sensitized photocurrent when adsorbed on a $\mathrm{SnO}_{2}$ nanocrystalline thin film in a photoelectrochemical cell [129]. The metalized and nonmetallized moieties showed different singlet state energies and redox properties. Complete 
singlet-singlet energy transfer from P-Zn to P was found in the dyad. Although being a suitable energy donor for the dyad molecule, the P-Zn moiety was found to be less efficient than $\mathrm{P}$ at photocurrent generation [124].

Porphyrin-rhodanine acetic acid dyads, with a rhodanine acetic acid group present either at the meso- or pyrrole- $\beta$-position, were synthesized [129], or characterized by cyclic voltammetry, UV-vis, and fluorescence spectroscopy. The redox capacities of these dyads were found to be altered due to the electron-withdrawing nature of the rhodanine acetic acid moiety. These dyes were tested in DSSCs using three different redox electrolytes. A solar-to-electrical energy conversion efficiency of $0.55 \%$ was observed for meso-Zn-rhodanine [125]. Porphyrin dimers were synthesized by some researchers [127]. A meso-meso-linked porphyrin dimer showed good photovoltaic act with a power alteration efficiency of 5.2\%. Different porphyrin-furan dyads were designed and synthesized by different group [157], which contained an anchoring group either at the meso-phenyl or pyrrole- $\beta$ position of a zinc porphyrin-based on the $\mathrm{D}-\pi-\mathrm{A}$ approach. The porphyrin macrocycle acts as the donor, a furan heterocycle acts as the $\pi$-spacer, and either cyanoacetic acid or malonic acid group acts as the acceptor. These dyads were fully characterized by UV-vis, ' $\mathrm{H}$ NMR, and fluorescence spectroscopies, as well as cyclic voltammetry [157]. Time-dependent DFT (TD-DFT) was used to simulate the UV-vis spectra of these dyads. A good correlation between the experimental and TD-DFT-calculated spectra was obtained. None of the redox capabilities of the dyads were changed in comparison with their separate ingredients. The dyads were tested in DSSCs; it was found that the pyrrole- $\beta$ substituted zinc porphyrins showed improved performance in comparison with the matching mesophenyl dyads [158], [159]. Optical band gap, natural bonding, and molecular bonding orbital (HOMO-LUMO) analyses were also performed.

Strongly coupled phenazine-porphyrin dyads with an anchoring group through which the dyad can interact with the surface of metal oxides were synthesized [160], and their spectral and photophysical properties were investigated experimentally. Quantum chemical calculations, as well as experimental measurements of these synthesized dyads, showed that they exhibit different absorption bands from those of the constituent chromophore units and absorb broadly from 300 to $636 \mathrm{~nm}$. Furthermore, a set of porphyrin-porphyrin and oxochlorin-oxochlorin dyads were prepared by group of scintest [161]. These dyads were tested using electrochemical 
techniques static, time-resolved absorption, and emission spectroscopy. The obtained results are useful for the design of multi-pigment constructions which absorb in the red region and undergo fast and effective energy transfer. Some examples of these dyads are shown in Fig. 6.

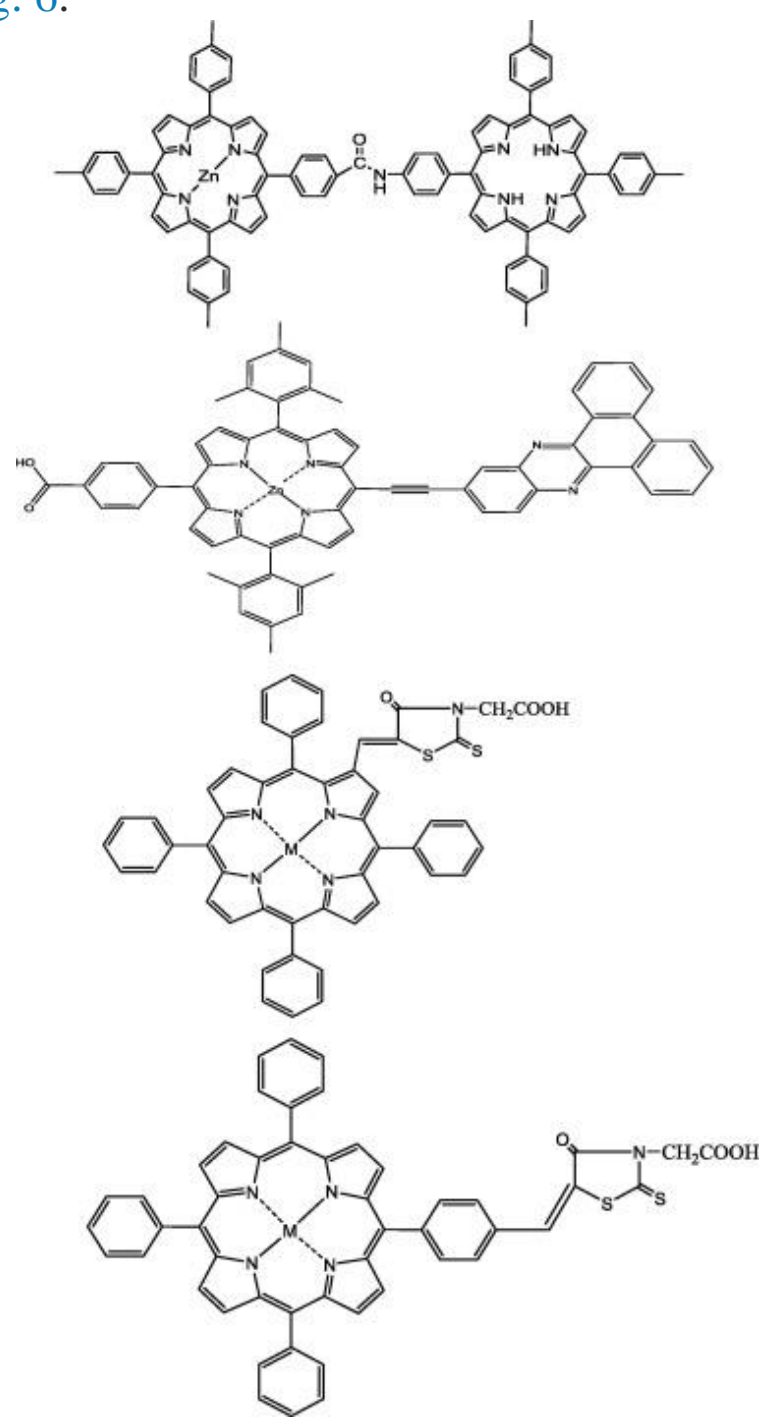

Fig. 6. Some investigated phenazine-porphyrin dyads.

\subsection{Density functional theory (DFT) and time-dependent DFT (TD-DFT) studies of the electronic and spectral properties of porphyrin-based dyes}

This section focuses on the use of DFT and TD-DFT to calculate the different electronic properties of porphyrin-based dyes concerning their use as sensitizers in DSSCs. Various computational quantum chemical methods have been used in this 
regard. For example, the Q and B bands of free-base, magnesium, and zinc porphyrins and their derivatives have been simulated using multireference Møller-Plesset perturbation (MRMP) theory with complete active space self-consistent field (CASSCF) reference functions [110]. It was found that the Q band in the visible region can be strengthened by specific chemical alterations to the basic structure of free-base porphyrin, such as external substituents, change in conjugation pathway, and change in the central substituent. The substitution of nitrogen atoms for meso-carbon atoms can shrink the central hole, whereas hydrogenation at the exocyclic double bond of the pyrrole rings can expand the central hole. The former was found to significantly intensify the oscillator strength of the higher energy side transition of the Q band, with the peak position unchanged [162]. Changing from metal-free to metalloporphyrins had a smaller effect on either the position or oscillator strength of the spectral bands [110].

Magnesium porphyrins have been studded using two spectroscopic methods (Multiconfigurational self-consistent field (MC-SCF) and second-order perturbation methods) [111]. Four allowable singlet states of $E_{1 u}$ symmetry for magnesium porphyrins were computed in addition to some prohibited transitions and a few triplet states. This led to a regular elucidation of the electronic spectrum. A discrepancy was noted between the calculated and measured values, which was attributed to restrictions in the basis set and the point that all measurements were made on porphyrins substituted with magnesium [163]. It is supposed that nonlinear distortions of the porphyrin skeleton yield substantial redshifts in the electronic absorption spectra due to planarity-induced destabilization of the porphyrin HOMOs [112]. Using TD-DFT and experimental examination was carried out on photophysics of the $\mathrm{S} 2$ and S1 excited states of porphyrin contains zinc and some of its derivatives such as quantum yields, steady-state absorption, fluorescence spectra, and excited-state lifetimes at room temperature in several solvents [163]. The radiative and radiationless degeneration constants of the fluorescent excited states reachable in the visible and near-UV areas of the spectrum were gained. TD-DFT calculations of the energies and equilibriums of the complete set of excited states reachable by 1- or 2photon absorption in the near-UV-vis region were also carried out. Substitution on the porphyrin macrocycle outline affected the ground state geometry and change the electron density distributions [124]; both, orbital energies and relative order of excited 
electronic states accessible in the near-UV-blue regions of the spectrum were also calculated.

To elucidate how the substituent affects the electronic structure and nature in the visible region for metalloporphyrins (series of $\beta$-substituted zinc porphyrins); the researcher used spectroscopic analysis such as DFT calculations, electronic absorption, and resonance raman spectroscopy [158]. The use of conjugated $\beta$ substituents was found to have a significant distortion to the frontier molecular orbitals nature and energy which led to the formation of additional molecular orbitals from the parent metalloporphyrin species [148]. The spectra of all species were typical of porphyrins, with additional transitions observed along with the Q and B bands seen in metalloporphyrins. The observed absorption bands could be rationalized by an extension of Gouterman's four-orbital model [164]. The excitations in the visible region were also determined using resonance Raman spectroscopy. The nature of the electronic transitions was shown to depend heavily on the type of $\beta$ substituent [165], which could aid the rational design of metalloporphyrins for DSSC applications.

Some researchers used DFT and TD-DFT for calculations of the electronic structures and electronic absorption spectra of a series of zinc porphyrin-based sensitizers [139]. Using simulation Dye- $\left(\mathrm{TiO}_{2}\right)_{36}$ anatase nanoparticle systems were tested to show their electronic structure on the interface, results showed that attaching a strong electron donor at the meso-position opposite to the anchoring group of the dye increases the molecular extinction coefficient, excited-state lifetime, and light-harvesting efficiency. Hence, the efficiency of the DSSC can be improved through structural modification of the sensitizing dye [139].

The performance of some acene-modified zinc porphyrin dyes (benzene to pentacene) as photosensitizers in DSSCs has been studied [166] to investigated their structural, electronic, and optical properties of the dyes at the DFT/TD-DFT levels in the presence of solvent and gas phase. $\mathrm{TiO}_{2}$-dye interface was investigated using both cluster and periodic models. Their results confirmed that the DFT functional used in valuing the important parameters for DSSCs should be cautiously checked, and their performances could be enhanced using specific energy-shift adjustment to compensate for the systematic errors. The best theoretical level for depicting the reduction potentials was found to be either the Minnesota functional with double the amount of 
nonlocal exchange (M06-2X) combined with the formula $\Delta \mathrm{E}_{\text {red }}=\left(\mathrm{E}^{0}-\mathrm{E}^{-}\right)_{\mathrm{GS}}$, or Becke's three-parameter hybrid exchange functional and Lee-Yang-Parr correlation functional (B3LYP) combined with Koopmans' theorem. On the other hand, the best practices for approximating the excitation energies were found to be the long-range corrected Perdew-Burke-Ernzerhof functional (LC- $\omega \mathrm{PBE}$ ). On the contrary to the choosing of DFT functional, both the cluster and periodic models led to consistent views of the dye- $\mathrm{TiO}_{2}$ interactions, showing that the use of either model should reach sensible results at least in a qualitative manner [167].

\section{Conclusions}

This review describes the different types of solar cells and the essential processes taking place in these photovoltaic devices, especially DSSCs. We also discussed the different possibilities for improving their light-to-electrical energy conversion performance such as structural modifications through introducing push-pull moieties, in turn tuning the HOMO-LUMO energy gap of the sensitizing dyes used in DSSCs. The kinetics of different steps taking place in the sensitization process comprise complex phenomena. However, the different theoretical approaches applied at different levels of theory reveal many essential features that could help in attaining reasonable efficiency of the DSSCs. These could be described out as follows.

The sensitizing dye should possess a LUMO above the conduction band edge of the metal oxide (usually nanocrystalline $\mathrm{TiO}_{2}$ ). This will result in possible electron injection from the excited dye molecule to the surface of the metal oxide. Also, its HOMO should lie below the redox potential of the electrolyte used $\left(\mathrm{I}^{-} / \mathrm{I}_{3}^{-}\right.$in most cases). This ensures dye regeneration after the electron transfer process. The dye molecule should absorb sunlight in the visible as well as IR regions with high absorptivity to attain high light-harvesting efficiency. Dyes containing a carboxylate group may anchor onto the metal oxide surface by the following binding modes: unidentate, chelating, or bridging bidentate. The most probable mode was found to be the bridging bidentate case. To improve the dye performance in the sensitization process, the aggregation of dye molecules should be minimized as much as possible. Both experimental and theoretical calculations of adsorption energies of the different 
dyes used for sensitization in DSSCs might be crucial in predicting the relative performance and efficiencies of these dyes.

\section{Declaration of Competing Interest}

The authors report no declarations of interest. This research did not receive any specific grant from funding agencies in the public, commercial, or not-for-profit sectors.

\section{References}

1. Seidel, R. W.; Oppel, I. M., 1D and 2D solid-state metallosupramolecular arrays of freebase 5,10,15,20-tetra(4-pyridyl)porphyrin, peripherally linked by zinc and manganese ions. Struct Chem 2009, 20 (1), 121-128.

2. Niu, W. Y.; Sun, J. W.; Yan, P. F.; Li, Y. X.; An, G. H.; Li, G. M., 2D 1-Di-toluoyl-tartaric acid Lanthanide Coordination Polymers: Toward Single-component White-Light and NIR Luminescent Materials. Chem-Asian J 2016, 11 (4), 555-560.

3. Seidel, R. W.; Oppel, I. M., 2D Metallosupramolecular Arrays of Zinc-5,10,15,20-tetra(4pyridyl)porphyrin via Self-complementary Coordination and Peripheral Linkage. Z Anorg Allg Chem 2010, $636(3-4), 446-448$.

4. Inoue, A.; Hosokawa, T.; Haishi, M.; Ohtani, N., 4-(dicyanomethylene)-2-methyl-6-(pdimethylaminostyryl)-4H-pyran (DCM)-doping density dependence of luminescence spectra and white emission in polymer light-emitting diodes. Phys Status Solidi C 2009, 6 (1), 334-337.

5. $\quad$ Han, C.; Shao, Q.; Liu, M.; Ge, S. S.; Liu, Q. Y.; Lei, J., 5,10,15,20-tetrakis(4chlorophenyl)porphyrin decorated $\mathrm{TiO} 2$ nanotube arrays: Composite photoelectrodes for visible photocurrent generation and simultaneous degradation of organic pollutant. Mat Sci Semicon Proc 2016, $56,166-173$.

6. $\quad$ Elgazzar, S.; Rusz, J.; Oppeneer, P. M.; Colineau, E.; Griveau, J. C.; Magnani, N.; Rebizant, J.; Caciuffo, R., Ab initio computational and experimental investigation of the electronic structure of actinide 218 materials. Phys Rev B 2010, 81 (23).

7. McDonald, J. F.; Mezencev, R.; Long, T. Q.; Benigno, B.; Bonta, I.; Del Priore, G., Accurate prediction of optimal cancer drug therapies from molecular profiles by a machine-learning algorithm. $J$ Clin Oncol 2015, 33 (15).

8. Huang, J. S.; Li, G.; Wu, E.; Xu, Q. F.; Yang, Y., Achieving high-efficiency polymer whitelight-emitting devices. Adv Mater 2006, 18 (1), 114-117.

9. Botu, V.; Ramprasad, R., Adaptive machine learning framework to accelerate ab initio molecular dynamics. Int J Quantum Chem 2015, 115 (16), 1074-1083.

10. Li, A.; Zhao, L. Z.; Hao, J.; Ma, R. J.; An, Y. L.; Shi, L. Q., Aggregation Behavior of the Template-Removed 5,10,15,20-Tetrakis(4-sulfonatophenyl)porphyrin Chiral Array Directed by Poly(ethylene glycol)-block-poly(L-lysine). Langmuir 2014, 30 (16), 4797-4805.

11. Wang, R. B.; Brugh, A. M.; Rawson, J.; Therien, M. J.; Forbes, M. D. E., Alkyne-Bridged Multi[Copper(II) Porphyrin] Structures: Nuances of Orbital Symmetry in Long-Range, Through-Bond Mediated, Isotropic Spin Exchange Interactions. J Am Chem Soc 2017, 139 (29), 9759-9762.

12. Li, Z. Z.; Sinha, S.; Treich, G. M.; Wang, Y. F.; Yang, Q. W.; Deshmukh, A.; Sotzing, G. A.; Cao, Y., All-organic flexible fabric antenna for wearable electronics. J Mater Chem C 2020, 8 (17), 56625667. 
13. Lee, J. S.; Kang, B. H.; Kim, S. H.; Lee, J. W.; Lee, S. W.; Kim, S. W.; Gopalan, S. A.; Kwon, J. B.; Bae, J. H.; Kim, E. S.; Kwon, D. H.; Kang, S. W., All-solution-processed high-brightness hybrid white quantum-dot light-emitting devices utilizing polymer modified quantum dots. Org Electron 2017, 42, 393-398.

14. High, J. S.; Virgil, K. K.; Jakubikova, E., Electronic Structure and Absorption Properties of Strongly Coupled Porphyrin-Perylene Arrays. J Phys Chem A 2015, 119 (38), 9879-9888.

15. Freeman, A. J., Electronic-Structure Theory in the New-Age of Computational Materials Science. Annu Rev Mater Sci 1995, 25, 1-5.

16. Jiang, H.; Hu, W. P., The Emergence of Organic Single-Crystal Electronics. Angew Chem Int Edit 2020, 59 (4), 1408-1428.

17. Carpenter, B. K.; Ezra, G. S.; Farantos, S. C.; Kramer, Z. C.; Wiggins, S., Empirical Classification of Trajectory Data: An Opportunity for the Use of Machine Learning in Molecular Dynamics. J Phys Chem B 2018, 122 (13), 3230-3241.

18. Zvezdin, A.; Di Mauro, E.; Rho, D.; Santato, C.; Khalil, M., En route toward sustainable organic electronics. Mrs Energy Sustain 2020, 7.

19. Zhu, P. H.; Wang, P. P.; Kan, T. L.; Sun, G. Q.; Zhang, Y.; Yu, J. H., An enhanced photoelectrochemical immunosensing platform: Supramolecular donor-acceptor arrays by assembly of porphyrin and C-60. Biosens Bioelectron 2015, 68, 604-610.

20. Wang, R.; Peng, J.; Qiu, F.; Yang, Y. L., Enhanced white-light emission from multiple fluorophores encapsulated in a single layer of diblock copolymer micelles. Chem Commun 2011, 47, 2787-2789

21. Ma, Z.; Wang, P.; Gao, Z.; Wang, R.; Khalighi, K., Ensemble of machine learning algorithms using the stacked generalization approach to estimate the warfarin dose. PloS one 2018, 13 (10), $\mathrm{e} 0205872$.

22. Novikov, A. V.; Kuznetsova, L. I.; Dremova, N. N.; Parfenov, A. A.; Troshin, P. A., Environment-friendly aqueous processing of [60]fullerene semiconducting films for truly green organic electronics. J Mater Chem C 2020, 8 (2), 495-499.

23. Li, J. L.; Cao, J. J.; Duan, L. L.; Zhang, H. L., Evolution of Isoindigo-Based Electron-Deficient Units for Organic Electronics: From Natural Dyes to Organic Semiconductors. Asian J Org Chem 2018, 7 (11), 2147-2160.

24. Rawson, J.; Angiolillo, P. J.; Therien, M. J., Exceptional delocalization of electrons in conjugated porphyrin arrays. Abstr Pap Am Chem S 2012, 244.

25. Yang, J.; Park, M.; Yoon, Z. S.; Hori, T.; Peng, X. B.; Aratani, N.; Dedecker, P.; Hotta, J. I.; Uji-I, H.; Sliwa, M.; Hofkens, J.; Osuka, A.; Kim, D., Excitation energy migration processes in cyclic porphyrin Arrays probed by single molecule spectroscopy. J Am Chem Soc 2008, 130 (6), 1879-1884.

26. Kim, P.; Ikeda, T.; Lim, J. M.; Park, J.; Lim, M.; Aratani, N.; Osuka, A.; Kim, D., Excitedstate energy relaxation dynamics of triply linked $\mathrm{Zn}(\mathrm{II})$ porphyrin arrays. Chem Commun 2011, 47 (15), 4433-4435.

27. Kim, T.; Oh, J.; Jiang, H. W.; Tanaka, T.; Osuka, A.; Kim, D., Exciton coupling dynamics in syn- and anti-type beta-beta linked Zn(II) porphyrin linear arrays. Phys Chem Chem Phys 2016, 18 (33), 23105-23110.

28. Hori, T.; Nakamura, Y.; Aratani, N.; Osuka, A., Exploration of electronically interactive cyclic porphyrin arrays. J Organomet Chem 2007, 692 (1-3), 148-155.

29. Aratani, N.; Osuka, A., Exploration of Giant Functional Porphyrin Arrays. B Chem Soc Jpn 2015, $88(1), 1-27$.

30. Titi, H. M.; Nandi, G.; Tripuramallu, B. K.; Goldberg, I., Exploring Supramolecular SelfAssembly of Tetraarylporphyrins by Halogen Interactions. 3. Tin(L)(2)(A(2)B(2)-Porphyrin) Arrays Supported by Concerted Halogen and Hydrogen Bonding. Cryst Growth Des 2015, 15 (6), 3063-3075. 31. Luzanov, A. V., Extended quasi-correlated orbitals with long-range effects: Application to organic single-molecule electronics. Funct Mater 2020, 27 (1), 147-158. 
32. Kim, J. W.; Jang, Y. H.; Ku, G. M.; Kim, S.; Lee, E.; Cho, K.; Lim, K. I.; Lee, W. H., Liquid coplanar-gate organic/graphene hybrid electronics for label-free detection of single and double-stranded DNA molecules. Org Electron 2018, 62, 163-167.

33. Vollbrecht, J.; Oechsle, P.; Stepen, A.; Hoffmann, F.; Paradies, J.; Meyers, T.; Hilleringmann, U.; Schmidtke, J.; Kitzerow, H., Liquid crystalline dithienothiophene derivatives for organic electronics. Org Electron 2018, 61, 266-275.

34. Tajima, K., Look beyond the surface: recent progress in applications of surface-segregated monolayers for organic electronics. Polym J 2019, 51 (11), 1117-1126.

35. Klain, C.; Linde, S.; Shikler, R.; Sarusi, G., Low work function Ca doped graphene as a transparent cathode for organic opto-electronics and OLEDs. Carbon 2020, 157, 255-261.

36. Bullard, G.; Tassinari, F.; Ko, C. H.; Mondal, A. K.; Wang, R.; Mishra, S.; Naaman, R.; Therien, M. J., Low-Resistance Molecular Wires Propagate Spin-Polarized Currents. J Am Chem Soc 2019, 141 (37), 14707-14711.

37. Jamal, S.; Goyal, S.; Shanker, A.; Grover, A., Machine Learning and Molecular Dynamics Based Insights into Mode of Actions of Insulin Degrading Enzyme Modulators. Comb Chem High T Scr 2017, 20 (4), 279-291.

38. Karamzadeh, R.; Karimi-Jafari, M. H.; Sharifi-Zarchi, A.; Chitsaz, H.; Salekdeh, G. H.; Moosavi-Movahedi, A. A., Machine Learning and Network Analysis of Molecular Dynamics Trajectories Reveal Two Chains of Red/Ox-specific Residue Interactions in Human Protein Disulfide Isomerase. Sci Rep-Uk 2017, 7.

39. Majumder, A.; Hasanuzzaman, M.; Ekbal, A.; Saha, S., Machine Learning Approach for Argument Extraction of Bio-molecular Events. 2012 National Conference on Computing and Communication Systems (Ncccs) 2012, 109-113.

40. Bolis, G.; Dipace, L.; Fabrocini, F., A Machine Learning Approach to Computer-Aided Molecular Design. J Comput Aid Mol Des 1991, 5 (6), 617-628.

41. Yilmaz, H. B.; Lee, C.; Cho, Y. J.; Chae, C. B., A Machine Learning Approach to Model the Received Signal in Molecular Communications. Int Black Sea Conf 2017, 52-56.

42. Bauer, B. E.; Chapman, D.; Critchlow, R.; Dietterich, T.; Jain, A.; Lathrop, R.; Park, J.; Lozanoperez, T., A Machine Learning Approach to Predicting Biological-Activity Based on Molecular Shape. Abstr Pap Am Chem S 1993, 206, 95-Comp.

43. Li, Z.; Omidvar, N.; Chin, W. S.; Robb, E.; Morris, A.; Achenie, L.; Xin, H. L., MachineLearning Energy Gaps of Porphyrins with Molecular Graph Representations. J Phys Chem A 2018, 122 (18), 4571-4578.

44. Peng, X. B.; Huang, Y. Y.; Gao, C.; Peng, J. B.; Komatsu, N.; Osuka, A.; Cao, Y., Macroscopic Films of Porphyrin Nanowell-Arrays via Solvent Diffusion-Induced Self-Assembly. J Phys Chem C 2010, 114 (43), 18449-18454.

45. Lee, J. H.; Jintoku, H.; Okazaki, Y.; Sagawa, T.; Takafuji, M.; Ihara, H., Manipulation of discrete porphyrin-fullerene nanopillar arrays regulated by the phase separated infiltration of polymer in ternary blended organic thin-films. Sol Energ Mat Sol C 2015, 140, 428-438.

46. Mitra, K. Y.; Alalawe, A.; Voigt, S.; Boeffel, C.; Baumann, R. R., Manufacturing of All InkjetPrinted Organic Photovoltaic Cell Arrays and Evaluating Their Suitability for Flexible Electronics. Micromachines-Basel 2018, 9 (12).

47. Huang, B.; von Lilienfeld, O. A., Many-body representations for machine learning models of molecular properties. Abstr Pap Am Chem S 2016, 252.

48. Teo, R. D.; Wang, R. B.; Smithwick, E. R.; Migliore, A.; Therien, M. J.; Beratan, D. N., Mapping hole hopping escape routes in proteins. P Natl Acad Sci USA 2019, 116 (32), 15811-15816.

49. Emandi, G.; Shaker, Y. M.; Flanagan, K. J.; O'Brien, J. M.; Senge, M. O., Merging Triptycene, BODIPY and Porphyrin Chemistry: Synthesis and Properties of Mono- and Trisubstituted Triptycene Dye Arrays. Eur J Org Chem 2017, (45), 6680-6692. 
50. Thamyongkit, P.; Muresan, A. Z.; Diers, J. R.; Holten, D.; Bocian, D. F.; Lindsey, J. S., MesoC-13-labeled porphyrins for studies of ground-state hole transfer in multiporphyrin arrays. J Org Chem 2007, 72 (14), 5207-5217.

51. Mori, H.; Osuka, A., meso-meso Directly-linked trimeric and pentameric electron-deficient porphyrin-hexaphyrin hybrid arrays. J Porphyr Phthalocya 2016, 20 (1-4), 245-253.

52. Mori, H.; Tanaka, T.; Lee, S.; Lim, J. M.; Kim, D.; Osuka, A., meso-meso Linked Porphyrin[26]Hexaphyrin-Porphyrin Hybrid Arrays and Their Triply Linked Tapes Exhibiting Strong Absorption Bands in the NIR Region. J Am Chem Soc 2015, 137 (5), 2097-2106.

53. Wang, J.; Gayatri, M. A.; Ferguson, A. L., Mesoscale Simulation and Machine Learning of Asphaltene Aggregation Phase Behavior and Molecular Assembly Landscapes. J Phys Chem B 2017, 121 (18), 4923-4944.

54. Zhang, S. M.; Kim, J. O.; Li, Y. J.; Wen, B.; Zhou, M. B.; Liu, S. B.; Aratani, N.; Xu, L.; Kim, D.; Song, J. X., meso-to-meso 2,5-Pyrrolylene bridged zig-zag porphyrin arrays. Chem Commun 2017, 53 (83), 11488-11491.

55. Heinonen, M.; Shen, H. B.; Zamboni, N.; Rousu, J., Metabolite identification and molecular fingerprint prediction through machine learning. Bioinformatics 2012, 28 (18), 2333-2341.

56. Wu, J.; Chen, J. H.; Wang, C.; Zhou, Y.; Ba, K.; Xu, H.; Bao, W. Z.; Xu, X. H.; Carlsson, A.; Lazar, S.; Meingast, A.; Sun, Z. Z.; Deng, H. X., Metal-Organic Framework for Transparent Electronics. Adv Sci 2020, 7 (8).

57. Yu, J. X.; Mathew, S.; Flavel, B. S.; Quinton, J. S.; Johnston, M. R.; Shapter, J. G., Mixed assembly of ferrocene/porphyrin onto carbon nanotube arrays towards multibit information storage. 2008 International Conference on Nanoscience and Nanotechnology 2008, 176-179.

58. Spiess, H., Role of conformation of side groups in supramolecular organization of materials for organic electronics. Abstr Pap Am Chem S 2019, 258.

59. Yang, J.; Lee, J. E.; Lee, C. Y.; Aratani, N.; Osuka, A.; Hupp, J. T.; Kim, D., The Role of Electronic Coupling in Linear Porphyrin Arrays Probed by Single-Molecule Fluorescence Spectroscopy. Chem-Eur J 2011, 17 (33), 9219-9225.

60. Kim, D., The Role of Electronic Coupling in Various Porphyrin Arrays Probed by Raman and Single Molecule Fluorescence Spectroscopy. Aip Conf Proc 2010, 1267, 687-688.

61. Yu, J. X.; Mathew, S.; Flavel, B. S.; Johnston, M. R.; Shapter, J. G., Ruthenium porphyrin functionalized single-walled carbon nanotube arrays - A step toward light harvesting antenna and multibit information storage. J Am Chem Soc 2008, 130 (27), 8788-8796.

62. Sizov, A. S.; Agina, E. V.; Ponomarenko, S. A., Self-assembled interface monolayers for organic and hybrid electronics. Russ Chem Rev+ 2019, 88 (12), 1220-1247.

63. Shen, Y. T.; Deng, K.; Li, M.; Zhang, X. M.; Zhou, G.; Muellen, K.; Zeng, Q. D.; Wang, C., Self-assembling in fabrication of ordered porphyrins and phthalocyanines hybrid nano-arrays on HOPG. Crystengcomm 2013, 15 (27), 5526-5531.

64. Morisue, M.; Hoshino, Y.; Shimizu, K.; Shimizu, M.; Kuroda, Y., Self-complementary doublestranded porphyrin arrays assembled from an alternating pyridyl-porphyrin sequence. Chem Sci 2015, 6 (11), 6199-6206.

65. Rauch, V.; Conradt, J.; Takahashi, M.; Kanesato, M.; Wytko, J. A.; Kikkawa, Y.; Kalt, H.; Weiss, J., Self-organized porphyrin arrays on surfaces: the case of hydrophilic side chains and polar surfaces. J Porphyr Phthalocya 2014, 18 (1-2), 67-75.

66. $\quad$ Park, S.; Heo, S. W.; Lee, W.; Inoue, D.; Jiang, Z.; Yu, K.; Jinno, H.; Hashizume, D.; Sekino, M.; Yokota, T.; Fukuda, K.; Tajima, K.; Someya, T., Self-powered ultra-flexible electronics via nano-grating-patterned organic photovoltaics. Nature 2018, 561 (7724), 516-+.

67. Kang, W. M.; Ma, X. M.; Hu, M.; Jia, Z. X.; Liu, H.; Cheng, B. W., Self-templating synthesis of a fluorescent porphyrin doped poly(methyl methacrylate) nano-array and its $\mathrm{HCl}$ gas sensing properties. Anal Methods-Uk 2016, 8 (35), 6489-6493. 
68. Wang, R., Significantly Improving the Prediction of Molecular Atomization Energies by an Ensemble of Machine Learning Algorithms and Rescanning Input Space: A Stacked Generalization Approach. J Phys Chem C 2018, 122 (16), 8868-8873.

69. Riniker, S.; Landrum, G. A., Similarity maps - a visualization strategy for molecular fingerprints and machine-learning methods. $J$ Cheminformatics 2013, 5 .

70. Yang, F.; Li, C.; Wei, Y. Z.; Yan, N. F.; Wang, X. H.; Liu, F.; You, S. Y.; Wang, J. Z.; Ma, W.; Li, W. W., A Simple, Small-Bandgap Porphyrin-Based Conjugated Polymer for Application in Organic Electronics. Macromol Rapid Comm 2018, 39 (21).

71. Wang, R.; Peng, J.; Qiu, F.; Yang, Y. L.; Xie, Z. Y., Simultaneous blue, green, and red emission from diblock copolymer micellar films: a new approach to white-light emission. Chem Commun 2009, (44), 6723-6725.

72. Kim, D.; Osuka, A., Single-Molecule Photophysical Properties of Various Directly Linked Porphyrin Arrays. Multiporphyrin Arrays: Fundamentals and Applications 2012, 1-54.

73. Park, M.; Yoon, M. C.; Yoon, Z. S.; Hori, T.; Peng, X. B.; Aratani, N.; Hotta, J. I.; Uji-i, H.; Sliwa, M.; Hofkens, J.; Osuka, A.; Kim, D., Single-molecule spectroscopic investigation of energy migration processes in cyclic porphyrin arrays. J Am Chem Soc 2007, 129 (12), 3539-3544.

74. Pinkerton, N. M.; Gindy, M. E.; Calero-DdelC, V. L.; Wolfson, T.; Pagels, R. F.; Adler, D.; Gao, D. Y.; Li, S. K.; Wang, R. B.; Zevon, M.; Yao, N.; Pacheco, C.; Therien, M. J.; Rinaldi, C.; Sinko, P. J.; Prud'homme, R. K., Single-Step Assembly of Multimodal Imaging Nanocarriers: MRI and Long-Wavelength Fluorescence Imaging. Adv Healthc Mater 2015, 4 (9), 1376-1385.

75. Shetti, V. S.; Pareek, Y.; Ravikanth, M., Sn(IV) porphyrin scaffold for multiporphyrin arrays. Coordin Chem Rev 2012, 256 (23-24), 2816-2842.

76. Dvivedi, A.; Pareek, Y.; Ravikanth, M., Sn-IV Porphyrin Scaffolds for Axially Bonded Multiporphyrin Arrays: Synthesis and Structure Elucidation by NMR Studies. Chem-Eur J 2014, 20 (15), 4481-4490.

77. Mardis, K. L.; Sutton, H. M.; Zuo, X. B.; Lindsey, J. S.; Tiede, D. M., Solution-State Conformational Ensemble of a Hexameric Porphyrin Array Characterized Using Molecular Dynamics and X-ray Scattering. J Phys Chem A 2009, 113 (11), 2516-2523.

78. Salzillo, T.; Rivalta, A.; Castagnetti, N.; D'Agostino, S.; Masino, M.; Grepioni, F.; Venuti, E.; Brillante, A.; Girlando, A., Spectroscopic identification of quinacridone polymorphs for organic electronics. Crystengcomm 2019, 21 (24), 3702-3708.

79. Xu, H.; Cao, K. D.; Ding, H. B.; Zhong, Q. F.; Gu, H. C.; Xie, Z. Y.; Zhao, Y. J.; Gu, Z. Z., Spherical Porphyrin Sensor Array Based on Encoded Colloidal Crystal Beads for VOC Vapor Detection. Acs Appl Mater Inter 2012, 4 (12), 6751-6756.

80. Cammidge, A. N.; Nekelson, F.; Hughes, D. L.; Zhao, Z. X.; Cook, M. J., Stepwise syntheses of complex mu-oxo-linked heterochromophore arrays containing phthalocyanine, porphyrin and subphthalocyanine ligands. J Porphyr Phthalocya 2010, 14 (12), 1001-1011.

81. Kang, B.; Song, E.; Lee, S. B.; Chae, B. G.; Ahn, H.; Cho, K., Stretchable Polymer Gate Dielectric with Segmented Elastomeric Network for Organic Soft Electronics. Chem Mater 2018, 30 (18), 6353-6360.

82. Ferdele, S.; Jose, B.; Foster, R.; Keyes, T. E.; Rice, J. H., Strong coupling in porphyrin Jaggregate excitons and plasmons in nano-void arrays. Opt Mater 2017, 72, 680-684.

83. Samanta, P. N.; Das, K. K., Structural and electronic properties of covalently functionalized 2aminoethoxy-metallophthalocyanine-graphene hybrid materials: a computational study. Rsc Adv 2015, 5 (104), 85730-85740.

84. Yoon, M. C.; Cho, S.; Kim, P.; Hori, T.; Aratani, N.; Osuka, A.; Kim, D., Structural Dependence on Excitation Energy Migration Processes in Artificial Light Harvesting Cyclic Zinc(II) Porphyrin Arrays. J Phys Chem B 2009, 113 (45), 15074-15082.

85. Hadjab, M.; Ibir, M.; Berrah, S.; Abid, H.; Saeed, M. A., Structural, electronic and optical properties for chalcopyrite semiconducting materials: ab-initio computational study. Optik 2018, 169, 6976. 
86. Kim, C.; Gwon, Y. J.; Kim, J.; Lee, T. S., Synthesis of fluorescent conjugated polymer nanoparticles and their immobilization on a substrate for white light emission. Polym Chem-Uk 2018, 9 (48), 5671-5679.

87. Golf, H. R. A.; Oltmanns, A. M.; Trieu, D. H.; Reissig, H. U.; Wiehe, A., Synthesis of Functionalized BODIPYs, BODIPY-Corrole, and BODIPY-Porphyrin Arrays with 1,2,3-Triazole Linkers Using the 4-Azido(tetrafluorophenyl)-BODIPY Building Block. Eur J Org Chem 2015, (19), 4224-4237.

88. Mori, G.; Aratani, N.; Osuka, A., Synthesis of three-dimensionally arranged porphyrin arrays via intramolecular meso-meso coupling. Tetrahedron 2007, 63 (33), 7916-7925.

89. Langford, S. J.; Woodward, C. P., Synthesis, characterisation and X-ray structure of a novel porphyrin array employing $\mathrm{Zn}-\mathrm{O}$ and $\mathrm{O}-\mathrm{H}$...O bonding motifs. Polyhedron 2007, 26 (2), 338-343.

90. Randhawa, V.; Singh, A. K.; Acharya, V., A systematic approach to prioritize drug targets using machine learning, a molecular descriptor-based classification model, and high-throughput screening of plant derived molecules: a case study in oral cancer. Mol Biosyst 2015, 11 (12), 3362-3377.

91. Mazlan, M.; Rahim, A.; Al Bakri, A. M. M.; Razak, W.; Zubair, A. F.; Najib, Y. M.; Azman, A. B., Thermal Management of Electronic Components by Using Computational Fluid Dynamic (CFD) Software, FLUENT (TM) in Several Material Applications (Epoxy, Composite Material \& Nano-silver). Adv Mater Res-Switz 2013, 795, 141-+.

92. Maeda, K.; Nitani, M.; Uno, M., Thermocompression bonding of conductive polymers for electrical connections in organic electronics. Polym J 2020, 52 (4), 405-412.

93. Bouamaied, I.; Stulz, E., Thieme Chemistry Journal Awardees - Where are They Now? Stabilisation of Porphyrins in Tetranucleotide-Bisporphyrin Arrays by Duplex Formation with Peptide Nucleic Acid. Synlett 2009, (18), 2913-2918.

94. Zhang, C. G.; Zhang, R. W.; Wang, Z. X.; Zhou, Z.; Zhang, S. B.; Chen, Z. F., Ti-Substituted Boranes as Hydrogen Storage Materials: A Computational Quest for Ideal Combination of Stable Electronic Structure and Optimal Hydrogen Uptake. Chem-Eur J 2009, 15 (24), 5910-5919.

95. Wang, R. B.; Ko, C. H.; Brugh, A. M.; Bai, Y. S.; Forbes, M. D. E.; Therien, M. J., Topology, Distance, and Orbital Symmetry Effects on Electronic Spin-Spin Couplings in Rigid Molecular Systems: Implications for Long-Distance Spin-Spin Interactions. J Phys Chem A 2020, 124 (37), 7411-7415. 96. Hathout, R. M.; Metwally, A. A., Towards better modelling of drug-loading in solid lipid nanoparticles: Molecular dynamics, docking experiments and Gaussian Processes machine learning. Eur J Pharm Biopharm 2016, 108, 262-268.

97. Zhao, Z. X.; Cammidge, A. N.; Cook, M. J., Towards black chromophores: mu-oxo linked phthalocyanine-porphyrin dyads and phthalocyanine-subphthalocyanine dyad and triad arrays. Chem Commun 2009, (48), 7530-7532.

98. Osuka, A., Towards meso-meso-Linked Porphyrin Arrays and meso-Aryl Expanded Porphyrins. Chem Rec 2015, 15 (1), 143-159.

99. Brennan, B. J.; Durrell, A. C.; Koepf, M.; Crabtree, R. H.; Brudvig, G. W., Towards multielectron photocatalysis: a porphyrin array for lateral hole transfer and capture on a metal oxide surface. Phys Chem Chem Phys 2015, 17 (19), 12728-12734.

100. Brown, A.; Jeffries-El, M., Towards the development of highly conjugated BDx systems for organic electronics. Abstr Pap Am Chem S 2018, 256.

101. Zani, L.; Dessi, A.; Franchi, D.; Calamante, M.; Reginato, G.; Mordini, A., Transition metalcatalyzed cross-coupling methodologies for the engineering of small molecules with applications in organic electronics and photovoltaics. Coordin Chem Rev 2019, 392, 177-236.

102. Yamada, Y.; Mihara, N.; Shibano, S.; Sugimoto, K.; Tanaka, K., Triply Stacked Heterogeneous Array of Porphyrins and Phthalocyanine through Stepwise Formation of a Fourfold Rotaxane and an Ionic Complex. J Am Chem Soc 2013, 135 (31), 11505-11508.

103. Dahms, K.; Senge, M. O., Triptycene as a rigid, 120 degrees orienting, three-pronged, covalent scaffold for porphyrin arrays. Tetrahedron Lett 2008, 49 (37), 5397-5399. 
104. Schroder, S.; Strunskus, T.; Rehders, S.; Gleason, K. K.; Faupel, F., Tunable polytetrafluoroethylene electret films with extraordinary charge stability synthesized by initiated chemical vapor deposition for organic electronics applications. Sci Rep-Uk 2019, 9.

105. Rhee, H.; Joo, T.; Aratani, N.; Osuka, A., Ultrafast energy transfer in the soret band of linear porphyrin arrays. Springer Ser Chem Ph 2007, 88, 480-+.

106. Ventura, B.; Flamigni, L.; Beyler, M.; Heitz, V.; Sauvage, J. P., Unusual Photoinduced Electron Transfer from a Zinc Porphyrin to a Tetrapyridyl Free-Base Porphyrin in a Noncovalent Multiporphyrin Array. Chem-Eur J 2010, 16 (29), 8748-8756.

107. Bagchi, A., Use of Machine Learning Features to Detect Protein-Protein Interaction Sites at the Molecular Level. Adv Intell Syst 2015, 340, 49-54.

108. Stone, T. J.; Pickles, J. C.; Fairchild, A. R.; Kristiansen, M.; Chalker, J.; Wilkhu, L.; Hargrave, D.; Jacques, T., The use of machine learning to develop a robust predictor of glioneuronal tumour molecular subtype. Neuropath Appl Neuro 2018, 44, 35-35.

109. Abdel-Aal, R. E.; Raashid, M., Using abductive machine learning for online vibration monitoring of turbo molecular pumps. Shock Vib 1999, 6 (5-6), 253-265.

110. Leonardi, M. J.; Palomaki, P. K. B.; Dinolfo, P. H., Using copper(I)-catalyzed azide-alkyne cycloaddition in the creation of triazole linked multi-porphyrin arrays. Abstr Pap Am Chem S 2010, 240. 111. Apostolakis, J.; Hofmann, D.; Lengauer, T., Using simple learning machines to derive a new potential for molecular modeling. Rational Approaches to Drug Design 2001, 125-134.

112. Bruce, R. C.; Wang, R. B.; Rawson, J.; Therien, M. J.; You, W., Valence Band Dependent Charge Transport in Bulk Molecular Electronic Devices Incorporating Highly Conjugated Multi[(Porphinato)Metal] Oligomers. J Am Chem Soc 2016, 138 (7), 2078-2081.

113. Korolkov, V. V.; Svatek, S. A.; Summerfield, A.; Kerfoott, J.; Yang, L. X.; Taniguchi, T.; Watanabe, K.; Champness, N. R.; Besley, N. A.; Beton, P. H., van der Waals-Induced Chromatic Shifts in Hydrogen-Bonded Two-Dimensional Porphyrin Arrays on Boron Nitride. Acs Nano 2015, 9 (10), 10347-10355.

114. Kim, K. S.; Lim, J. M.; Osuka, A.; Kim, D., Various strategies for highly-efficient two-photon absorption in porphyrin arrays. J Photoch Photobio C 2008, 9 (1), 13-28.

115. Seo, D. G.; Lee, Y.; Go, G. T.; Pei, M.; Jung, S.; Jeong, Y. H.; Lee, W.; Park, H. L.; Kim, S. W.; Yang, H.; Yang, C.; Lee, T. W., Versatile neuromorphic electronics by modulating synaptic decay of single organic synaptic transistor: From artificial neural networks to neuro-prosthetics. Nano Energy 2019, 65 .

116. Zhang, L.; Ai, H. X.; Li, S. M.; Qi, M. Y.; Zhao, J.; Zhao, Q.; Liu, H. S., Virtual screening approach to identifying influenza virus neuraminidase inhibitors using molecular docking combined with machine-learning-based scoring function. Oncotarget 2017, 8 (47), 83142-83154.

117. Zhao, P.; Zhu, L. L., Virtual special issue: Organic and polymer materials for electronics. Chinese Chem Lett 2018, 29 (12), 1706-1708.

118. Long, J.; Xu, J. H.; Xia, S., Volatile Organic Compound Colorimetric Array Based on Zinc Porphyrin and Metalloporphyrin Derivatives. Enrgy Proced 2011, 12.

119. Uttiya, S.; Pratontep, S.; Bhanthumnavin, W.; Buntem, R.; Kerdcharoen, T., Volatile Organic Compound Sensor Arrays Based on Zinc Phthalocyanine and Zinc Porphyrin Thin Films. 2008 2nd Ieee International Nanoelectronics Conference, Vols 1-3 2008, 618-+.

120. Jordan, E. J.; Radhakrishnan, R., We Can Predict the Effects of Kinase Domain Mutations using Molecular Dynamics and Machine Learning. Biophys J 2017, 112 (3), 322a-322a.

121. Zhang, Y. F.; Xu, Z.; Zhang, F. J.; Wang, Y.; Zhao, S. L., White organic light emitting device with dyestuff DCJTB mended in polymer. Spectrosc Spect Anal 2008, 28 (4), 760-762.

122. Meng, L. C.; Lou, Z. D.; Yang, S. Y.; Hou, Y. B.; Teng, F.; Liu, X. J.; Li, Y. B., White organic light-emitting diodes based on a combined electromer and monomer emission in doubly-doped polymers. Chinese Phys B 2012, 21 (8). 